\title{
Estudio de caso: Concesión vial Cartagena-Barranquilla y Circunvalar de la Prosperidad. Análisis de política pública ${ }^{1}$
}

\author{
SANDRA Milena VÉLeZ OrTiZ ${ }^{2}$
}

\section{RESUMEN}

El contrato de concesión vial denominado Concesión Cartagena-Barranquilla y la Circunvalar de la Prosperidad fue tomado como modelo para un estudio de manejo de riesgo en los nuevos modelos de contratos de concesión vial de Cuarta Generación celebrados

1 Fecha de recepción: 18 de abril de 2018. Fecha de aceptación: 30 de mayo de 2018. Para citar el artículo: VÉLEZ ORTIZ, S. "Estudio de caso: Concesión vial Cartagena-Barranquilla y Circunvalar de la Prosperidad: análisis de política pública", en Revista Con-texto n. ${ }^{\circ}$ 49, pp. 173-207. DOI: https://doi.org/10.18601/01236458.n49.08

2 Abogado y Administrador de Empresas de la Universidad de Cartagena, con dominio del inglés y francés. Especialista en Derecho Administrativo, Universidad Externado de Colombia; ${ }_{\text {MBA Dirección }}$ General Instituto Europeo de Postgrado y Universidad San Pablo CEU de Madrid, Magíster en Análisis de Problemas Políticos, Económicos y Relaciones Internacionales, de la Universidad Externado de Colombia en convenio con el IHEAL de la Universidad de París III. Esta investigación recoge los aspectos más importantes de la tesis que fue presentada para acceder al grado de Magíster en Análisis de Problemas Políticos. Actualmente, se desempeña como funcionaria de la Dirección de Vigilancia Fiscal de la Contraloría Delegada para el Sector Minas y Energía. Esta investigación fue desarrollada entre los años 2013-2017, y en la actualidad, conforme a página web de la ANI (Recuperado de http://www.ani. gov.co/proyecto/carretero/autopista-cartagena-barranquilla-y-circunvalar-de-la-prosperidad-21269), el contrato se encuentra en gestión contractual-construcción, y a registros de prensa el viaducto de la ciénaga de la Virgen estaría habilitado a finales de este semestre y la unión de los tramos faltantes se hizo el 21 de marzo de 2018, y todavía quedan pendientes predios sin restituir y el cumplimiento de las compensaciones con las comunidades afectadas por el proyecto, como son Puerto Rey, Villa Gloria, La Boquilla y Tierra-Baja. En cuanto al resto de proyectos 4G, el escándalo de Odebrecht y la situación jurídica de Carlos Solarte ha desatado la configuración del riesgo reputacional. Recuperado de http:// www.eluniversal.com.co/cartagena/viaducto-se-habilitara-finales-de-este-semestre-272793 http://www. eluniversal.com.co/cartagena/presidente-santos-vertera-ultima-losa-del-viaducto-274178 http://www. dinero.com/edicion-impresa/pais/articulo/obstaculos-en-la-financiacion-de-los-proyectos-4g/256344. Correo-e: sandvelez@gmail.com 
bajo la modalidad de Asociaciones Público Privadas -APP-, en aras de analizar todas las variables utilizadas para la implementación de ese programa vial tan ambicioso.

Este estudio arroja como resultado que la disminución de la TIR de $14,71 \%$ a 13,3\% le permite a la entidad tener cierta ventaja para la renegociación de los términos del contrato.

Palabras clave: Contrato de concesión, Políticas públicas, Riesgo, Infraestructura.

\section{CASE-STUDY: CARTAGENA-BARRANQUILLA AND CIRVUNVALAR DE LA PROSPERIDAD 'S HIGHWAY CONCESSION. PUBLIC POLICY ANALYSIS}

\section{ABSTRACT}

The road concession contract called Concession Cartagena-Barranquilla and Circunvalar of the Prosperity was taken as a model for a risk management study in the new models of 4 th-generation-road-concession-contract written as private-Public-Partnership in order to analyze all kinds of variables used for implementation of this ambitious road program.

This study leads to a result of diminution of the internal rate of return from $14.71 \%$ to $13.3 \%$ in order to give the state authority a leverage for renegotiation of the contract terms.

Keywords: Concession Contract, Public Politics, Risk managment, Infraestructure.

\section{ANTECEDENTES}

El 18 de septiembre de 2012, el Gobierno Nacional, como parte de los compromisos del Plan Nacional de Desarrollo 2010-2014 "Prosperidad para todos", para impulsar la locomotora de infraestructura de transporte presentó el Plan de Concesiones Viales de Cuarta Generación, que fue desarrollado mediante las leyes 1508 de 2012 y 1682 de 2013 , en el cual se proyectaba hacer, a cifras de 2012, una inversión total de $\$ 43,9$ billones de pesos y pasar de 745 kilómetros de dobles calzadas que tenía el país en 2010 a 1.773 en 2014 y luego a 3.400 en 2018 (Anónimo, 2013, p. 2).

Puesto que, conforme al portal Oxford Analytica, que cita el blog del Banco Interamericano de Desarrollo en materia de infraestructura Infralatam, la inversión en Colombia y en América Latina ha sido baja en los últimos años, lo que se debe, entre otros factores, a la caída de los precios de los commodities; en Colombia, durante los años 2010-2013, la inversión en infraestructura ha sido de 2,98\% del PIB, ubicándose en la posición 10 de 15 países latinoamericanos estudiados, lo que ha dado un total de $\$ 12,9$ millones USD, tal como lo muestra la siguiente gráfica: 


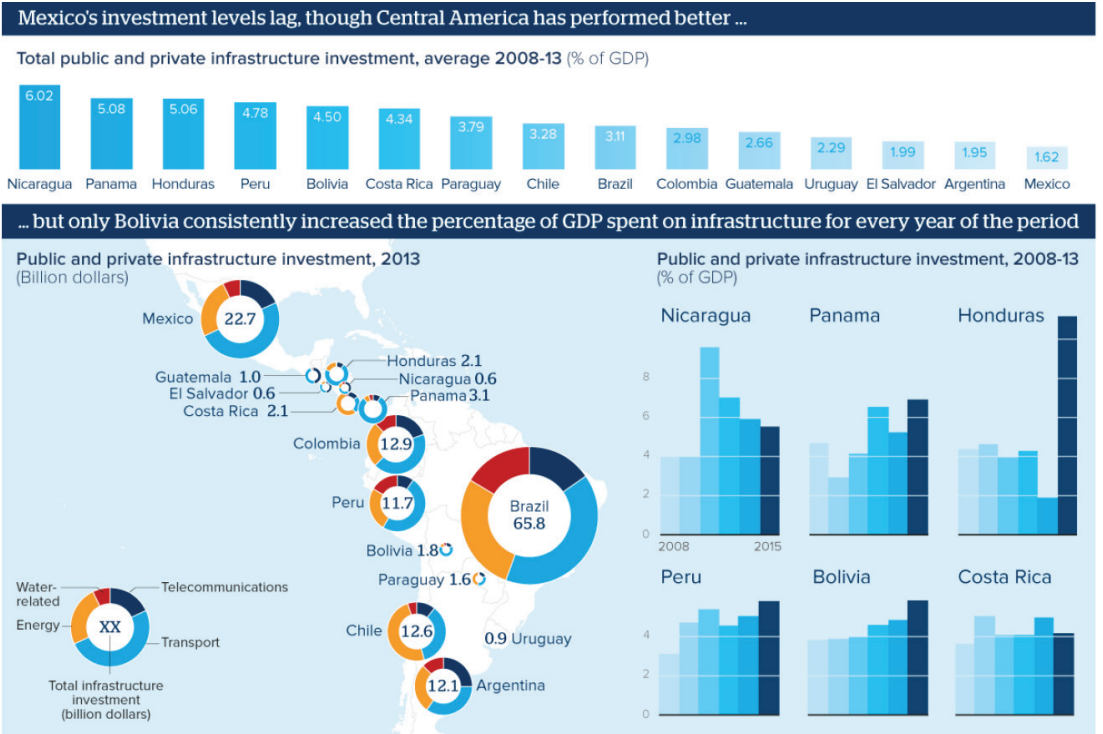

Fuente: Oxford Analytica (2016). 2.

\section{EL CONTRATO DE CONCESIÓN BAJO EL ESQUEMA APP}

El contrato de concesión bajo el esquema de Asociación Público-Privada, o concesión APP, que es el contrato bajo el cual operan las concesiones de Cuarta Generación, presenta una novedad frente a la distribución de riesgos, pues estos en su mayoría son transferidos al privado, el cual es el eje central del desarrollo de la política pública en materia de infraestructura de transporte en Colombia.

Este contrato de concesión vial ha sufrido grandes transformaciones en Colombia, ya que en la primera generación (1994-1997) se ofrecían garantías de ingreso mínimo y reconocimiento de sobrecostos a favor de los privados; en la segunda generación (1999-2001), se dieron mayores equilibrios entre los riesgos asumidos por el privado y el sector público, y se incorpora el concepto de plazo variable (se revierte a la Nación cuando el concesionario obtiene el ingreso esperado en la Concesión por el recaudo de peajes), y la tercera generación (2002-2010) se incorporó el criterio de gradualidad de la inversión, en la cual su ejecución depende de la demanda de tráfico (VILLARREAL, 2016).

En cuanto al análisis de las concesiones de primera, segunda y tercera generación, todos los modelos coinciden en presentar deficiencias en la fase de planeación de la concesión, en particular del esquema contractual adoptado y la inadecuada distribución de los riesgos. De hecho, la Contraloría General de la República, citando a la Procuraduría General de la Nación, elaboró un informe que estipula unas falencias estructurales en el modelo financiero, en los siguientes términos: 
TABLA 1. FALENCIAS EN LOS MODELOS DE CONCESIONES

\begin{tabular}{|l|l|}
\hline \multicolumn{1}{|c|}{ Elementos } & \multicolumn{1}{c|}{ Fundamento } \\
\hline $\begin{array}{l}\text { Elementos } \\
\text { del contrato } \\
\text { de concesión }\end{array}$ & $\begin{array}{l}\text { No se analizan a cabalidad los elementos del contrato de concesión, frente a la } \\
\text { necesidad que debe atender la entidad contratante, y se tramita como tal la simple } \\
\text { prestación de servicios o la construcción de una determinada obra, pero la entidad } \\
\text { contratante entrega la totalidad de los recursos para el efecto, así como los diseños, } \\
\text { permisos y licencias y demás información necesaria, de lo cual resulta que el } \\
\text { concesionario se limita a ejecutarla. }\end{array}$ \\
\hline Inversiones & $\begin{array}{l}\text { No se estudian, ni cuantifican, las inversiones que debe efectuar el concesionario, } \\
\text { para prestar el servicio o explotar el bien público. }\end{array}$ \\
\hline $\begin{array}{l}\text { Implicaciones } \\
\text { técnicas }\end{array}$ & $\begin{array}{l}\text { No se tienen en cuenta, las implicaciones técnicas de la contratación, ni los } \\
\text { aspectos sustanciales para su correcta ejecución. (p. ej., conflictos jurídicos } \\
\text { existentes sobre bienes del Estado y la necesidad de tramitar licencias, entre otros). }\end{array}$ \\
\hline Riesgos & $\begin{array}{l}\text { No se analizan en debida forma los riesgos que conlleva la ejecución del contrato, } \\
\text { más aún, teniendo en cuenta la complejidad técnica y económica, que implica en } \\
\text { materia de riesgos, pues no se identifican la totalidad de los riesgos previsibles, y no } \\
\text { se estiman las probabilidades de su ocurrencia y su valor frente al costo del contrato } \\
\text { (pp. 84-86). }\end{array}$ \\
\hline
\end{tabular}

Fuente: Contraloría General de la República (2011, pp. 84-86).

Más allá de lo dispuesto en la Ley 1508 de 2012, la Ley 1682 de 2013 y el Conpes 3760 de 2013, que son las normas más importantes en materia de concesiones de cuarta generación en Colombia, es importante mencionar las características más importantes de un contrato de concesión bajo el esquema APP:

- El riesgo de diseño y construcción lo asume el concesionario y el riesgo de mercado y tarifas lo asume el Estado.

- El flujo de información disponible para el Estado no es la misma que para el privado (asimetría de información), ante lo cual el Estado deberá enfrentarse a situaciones tales como la selección adversa, el riesgo moral, el conflicto de agencia ${ }^{3}$ (VILLARREAL, 2016) y, por tanto, debe procurar siempre blindar el proceso y garantizar su transparencia.

3 El conflicto de agencia puede definirse en una empresa privada, cuando el dueño es al mismo tiempo el administrador $;$ el problema de agencia no existe, dado que en este caso los intereses del accionista y el administrador son iguales, al ser la misma persona. Por otra parte, cuando son varios los accionistas de la empresa (más aún si es pública, por lo que la propiedad está atomizada), surge el problema de agencia. En este caso, estando los derechos de propiedad de la empresa perfectamente definidos, está en el interés de los accionistas nombrar un consejo de administración que, a través de un cuerpo directivo, opere la empresa. En este caso, el interés del administrador puede no estar alineado totalmente con el interés de los accionistas, que es maximizar las utilidades de la empresa. Los accionistas estarán dispuestos a sacrificar algo de las utilidades para no tenerse que involucrar con los costos que ello implica, en el manejo directo de la empresa. Obviamente esto tiene un límite. Si la pérdida de utilidades es mayor que el costo de manejar directamente la empresa, los accionistas tendrán el incentivo para cambiar al administrador, más cuando existe el peligro de una adquisición no solicitada por parte de empresas competidoras. Recuperado de https://www.eleconomista.com.mx/opinion/Problema-de-agencia-20160321-0014.html 
- Alto apalancamiento financiero por parte de la banca (tanto por créditos convencionales como financiación de organismos multilaterales). Esto se explica porque, conforme a un estudio del Banco Interamericano de Desarrollo, la infraestructura de América Latina y el Caribe ha sido tradicionalmente financiada a través de deuda; sin embargo, con la crisis financiera, el equity ganó terreno al final de la última década. No obstante, es importante tener en cuenta que casi todo el financiamiento de la deuda es extrabursátil (transacciones que se llevan a cabo directamente entre dos partes sin pasar por la bolsa de valores), un claro indicativo de la falta de profundidad de los mercados de la región (Banco Interamericano de Desarrollo, 2015).

Sin embargo, es importante tener en cuenta aspectos cruciales del mismo como el caso del riesgo de la demanda de tráfico, que tuvo algunos cambios significativos en el nuevo modelo de concesiones. Los riesgos de la demanda de tráfico tienen 3 fuentes: errores provenientes de predicciones de la demanda de tráfico, incertidumbre proveniente de errores en la determinación del crecimiento del tráfico actual y el tráfico inducido en los modelos que presente el concesionario; y los errores voluntarios cuyo origen son las predicciones optimistas en las proyecciones de demanda de tráfico, tergiversaciones estratégicas de las predicciones establecidas en el modelo financiero provenientes del contratista, o motivadas por incentivos políticos, o motivadas para ganar la concesión de un oferente en particular a través de la presentación de una oferta demasiado optimista o de una oferta que está direccionada a favorecer a un empresario en particular, y que guarda relación con la asimetría de información (BULL, 2017).

Para el caso particular de los errores voluntarios, el gobierno está obligado a tomar medidas, tales como: preparar un estudio de tráfico con consultores independientes, que sirva de parámetro de comparación con las ofertas presentadas; hacer evaluaciones comparativas independientes para los estudios de tráfico, compartir la información de la línea de base de los modelos de demanda de tráfico con los oferentes, penalizar a los oferentes que excedan las predicciones del gobierno, minimizar al máximo los vacíos legales que se puedan presentar en la regulación normativa referente a concesiones (BULL, 2017). Además, por su estructura, es inevitable que ocurra la renegociación, la cual debe hacerse con fundamento en razones de interés público.

Es importante resaltar que, hasta el momento, los proyectos han tenido dificultades para conseguir el cierre financiero, ya que, conforme a cifras de la Financiera de Desarrollo Nacional, solo 7 proyectos tenían cierre financiero a noviembre de 2016 y para fines de 2017, se esperaba completar esa cifra a 12 proyectos (Anónimo, 2017), debido, entre otras cosas, a que el sistema de equity en su mayoría no proviene de fondos propios del concesionario, sino de fondos especializados como la banca de inversión, organismos multilaterales e instituciones gubernamentales como la Financiera de Desarrollo Nacional. A esto habría que agregarle que la intención del gobierno era que los grandes fondos de capital privado e inversionistas internacionales entraran en estos consorcios desde una etapa muy inicial de los proyectos, lo cual no se ha logrado totalmente, salvo por el caso de Goldman Sachs, cuyos ingresos subieron un 50\% en 2016 gracias a su 
participación en la financiación de USD $\$ 1.200$ millones para tres proyectos del programa de infraestructura 4G, incluyendo nuestro estudio de caso (Dinero, 2016).

\section{PROYECTO OBJETO DE ESTUDIO}

El estudio de caso está compuesto por el contrato 004 de 2014, que corresponde al proyecto de la concesión de 4G.

Las vías objeto de la Concesión Corredor Cartagena-Barranquilla y Circunvalar de la Prosperidad tienen una longitud total estimada origen-destino de 146,6 kilómetros, discriminados así: Cartagena-Barranquilla, 109,9 km (Tramo 1), y la Circunvalar de la Prosperidad entre Barranquilla y Malambo (Tramo 2), con 36,7 kilómetros, que atraviesan los sectores Las Flores-Vía al Mar, Vía al Mar-Vía Juan Mina, Vía Juan Mina-La Cordialidad, La Cordialidad-Malambo. Ambos tramos, en su recorrido, atraviesan los departamentos de Bolívar y Atlántico (Agencia Nacional de Infraestructura, 2015).

Se busca, en principio, ampliar la concesión vial existente entre Cartagena y Barranquilla, debido, entre otros aspectos, a que la concesión está por finalizar en el año 2019 y está al tope de adiciones, pues fue una concesión de primera generación, adjudicada en el año 1994, y que tuvo problemas en su ejecución que terminaron en escenarios de renegociación. En la siguiente ficha técnica, se encuentran los datos básicos del proyecto objeto de estudio:

TABLA 2. FICHA TÉCNICA PROYECTO APP

\begin{tabular}{|c|}
\hline Autopista Cartagena-Barranquilla y Circunvalar de la Prosperidad \\
\hline FICHA TÉCNICA PROYECTO ANI \\
\hline OBJETO: \\
\hline $\begin{array}{c}\text { Financiación, elaboración de estudios y diseños definitivos, gestión ambiental, gestión predial, } \\
\text { gestión social, construcción, rehabilitación, mejoramiento, operación y mantenimiento del } \\
\text { corredor Proyecto Cartagena-Barranquilla y Circunvalar de la Prosperidad, de acuerdo con el } \\
\text { Apéndice Técnico } 1 \text { y demás apéndices del Contrato. }\end{array}$ \\
\hline $\begin{array}{c}\text { Longitud concesionada: } 146,6 \text { km } \\
\text { Doble calzada contratada:46,87 km } \\
\text { Segunda calzada: 6,95 km Mejoramiento: } 88,48 \text { km }\end{array}$ \\
\hline CONTRATISTA: \\
\hline Concesión Costera - Cartagena Barraquilla SAS \\
\hline ESTADO: \\
\hline Gestión contractual - Construcción \\
\hline No. contrato: \\
\hline $004-2014$ \\
\hline
\end{tabular}




\begin{tabular}{|c|}
\hline Fecha acta inicio: \\
\hline Martes, 4 de noviembre de 2014 \\
\hline Fecha suscripción contrato: \\
\hline Miércoles, 10 de septiembre de 2014 \\
\hline Año terminación contrato: \\
\hline 2039 \\
\hline Tiempo estimado concesión: 25 años \\
\hline VALOR \\
\hline \$1.709.364.530.216, dic. 2012 \\
\hline Interventor: \\
\hline Mab Ingeniería de valor \\
\hline $\begin{array}{l}\text { Cierre financiero: 8 de julio de 2016, por Goldman Sachs, por } \$ 1.462 \text { billones COP, de los cuales el } \\
\text { total de ese valor corresponde a deuda. Se emitieron us } \$ 472 \text { millones de bonos de deuda. }\end{array}$ \\
\hline
\end{tabular}

Fuente: Agencia Nacional de Infraestructura página web Recuperado de : http://www.ani.gov.co/modo-carreteras

\section{Información adicional del cierre financiero}

El desglose del cierre financiero otorgado por GOLDMAN SACHS está discriminado de la siguiente manera:

1. US $\$ 150,8$ millones en bonos de deuda a una tasa de $6,75 \%$

2. $\$ 327$ billones cop en UVR tasados en UVR $+6,25 \%$

3. \$135 billones COP en UVR a través de un crédito de la CAF-Corporación Andina de Fomento- a una tasa UVR $+7,40 \%$

4. \$250 billones COP denominados "préstamo $\mathrm{A}^{\prime}$, a través de Bancolombia, tasados por IPC $+7,50 \%$, con el compromiso de bajar al 7\% después de la construcción.

5. \$300 billones COP denominados préstamo B, aportados por Banco de Bogotá y Banco de Occidente, tasados al IPC + 9\%, con el compromiso de bajar al 6\% después de la construcción (FITZMAURICE, 2016). 
GRÁFICA 1. VALOR DE VIGENCIAS FUTURAS EN MILLONES DE PESOS APORTES ESTATALES

\begin{tabular}{|l|c|c|c|c|}
\hline \multicolumn{5}{|c|}{ D. Valor de vigencias futuras ( Millones de pesos ) } \\
\hline $\begin{array}{l}\text { Valor Aportes Estatales } \\
\text { para el Periodo de } \\
\text { Gobierno }\end{array}$ & 2015 & 2017 & 2018 & 2019 \\
\cline { 2 - 5 } & $24,889,975$ & $73,596,119$ & $104,172,094$ & $104,172,094$ \\
\hline
\end{tabular}

Fuente: Agencia Nacional de Infraestructura Recuperado de http://www.ani.gov.co/modo-carreteras

TABLA 3. PORCENTAJE PARTICIPACIÓN DE CONTRATISTAS CONTRATO 004 DE 2014 (CONTRATO APP)

\begin{tabular}{|l|c|}
\hline $\begin{array}{c}\text { Contratista (Accionistas propietarios de la Sociedad de Propósito } \\
\text { Especial Concesión Costera Cartagena-Barranquilla SAS) }\end{array}$ & $\begin{array}{c}\text { Porcentaje participación } \\
\text { contratista \% }\end{array}$ \\
\hline Mhc Ingeniería y Construcciones de Obras Civiles SAS & 30 \\
\hline Constructora Colpatria S.A. & 30 \\
\hline Constructora Meco SAS & 30 \\
\hline Castro Tcherassi S.A. & 10 \\
\hline
\end{tabular}

Fuente: Agencia Nacional de Infraestructura (página consultada el 31 de mayo de 2016) Recuperado de https://www. ani.gov.co/proyecto/carretero/autopista-cartagena-barranquilla-y-circunvalar-de-la-prosperida d-21269

Las Unidades Funcionales de este proyecto corresponden a los siguientes tramos (Agencia Nacional de Infraestructura, 2015, p. 6):

TABLA 4. UNIDADES FUNCIONALES CONTRATO 004 DE 2014 APP

\begin{tabular}{|c|c|c|c|}
\hline UF & Inicio & Fin & Descripción General de Intervención Inicial \\
\hline 1 & $\begin{array}{l}\text { Conexión con } \\
\text { Avenidad Santander }\end{array}$ & PR4+434 & $\begin{array}{l}\text { Operación y mantenimiento del anillo Vial de } \\
\text { Crespo (Túnel de Drespo). Construcción de los } \\
\text { puentes de la Bocana y las Américas. Construcción } \\
\text { de segunda calzada y ciclovía. }\end{array}$ \\
\hline 2 & PR1+905 & PR7 +500 & $\begin{array}{l}\text { Construcción de segunda calzada mediante } \\
\text { viaductos en la dirección Cartagena - Barranquilla. }\end{array}$ \\
\hline 3 & PR7+500 & PR97+150 & $\begin{array}{l}\text { Operación y Mantenimiento de doble calzada } \\
\text { existente. Rehabilitación de calzada sencilla actual. }\end{array}$ \\
\hline 4 & PR7 +150 & PR109+133 & Mejoramiento de doble calzada sencilla \\
\hline 5 & $\begin{array}{l}\text { PR68+000 de la vía } \\
2516\end{array}$ & $\begin{array}{l}\text { PR112+300 de } \\
\text { la vía } 906\end{array}$ & $\begin{array}{l}\text { Construcción de doble calzada de la circunvalar } \\
\text { entre Malambo y Galapa. }\end{array}$ \\
\hline 6 & $\begin{array}{l}\text { PR112+300 de la vía } \\
9006\end{array}$ & $\begin{array}{l}\text { Glorieta de la } \\
\text { Flores }\end{array}$ & $\begin{array}{l}\text { Construcción de doble calzada de la circunvalar } \\
\text { entre Galapa - intersección con la vía al Mar - } \\
\text { Glorieta de las Flores. }\end{array}$ \\
\hline
\end{tabular}

Fuente: Recuperado de http://www.concesioncostera.com/nuestro_proyecto.html 
Ahora bien, con el propósito de hacer una comparación entre ambos contratos, se presentará a continuación la ficha técnica del contrato de concesión actual que opera en la zona objeto del proyecto en estudio.

\section{CONTRATO DE CONCESION ACTUAL}

Este contrato tiene por objeto la realización por el sistema de concesión, el diseño, construcción, operación y mantenimiento del tramo de carretera Lomita Arena - Puerto Colombia-Barranquilla de la ruta 90 A y del empalme ruta 90 (La Cordialidad)-Lomita Arena y el mantenimiento y la operación del tramo Cartagena-Lomita Arena en los Departamentos de Bolívar y Atlántico. El acta de inicio de la obra fue el 8 de septiembre de 1994, es una concesión a 25 años, y tuvo 41 cambios en su contrato entre adiciones y modificatorios.

\section{CONSORCIO VÍA AL MAR S.A.}

TABLA 5. FICHA TÉCNICA CONTRATO 503 DE 1994

\section{CONCESIÓN}

\section{CARTAGENA - BARRANQUILLA}
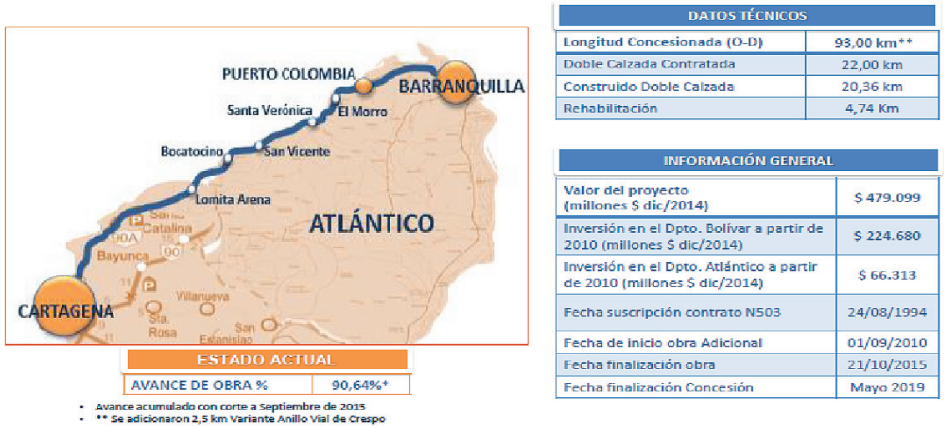

Fuente: Agencia Nacional de Infraestructura. Recuperado de https://www.ani.gov.co/proyecto/carretero/cartagenabarranquilla-21256

TABLA 6. DATOS FINANCIEROS CONTRATO 503 DE 1994 - CONCESIÓN VÍA AL MAR

\begin{tabular}{|c|c|c|c|c|c|}
\hline $\begin{array}{c}\text { Contrato 503 } \\
\mathbf{1 9 9 4}\end{array}$ & $\begin{array}{c}\text { Periodo etapa } \\
\text { construcción }\end{array}$ & $\begin{array}{c}\text { Periodo etapa } \\
\text { operación y } \\
\text { mantenimiento }\end{array}$ & $\begin{array}{c}\text { Fecha estimada de } \\
\text { reversión }\end{array}$ & $\begin{array}{c}\text { Valor inicial } \\
\text { millones COP }\end{array}$ & $\begin{array}{c}\text { Valor } \\
\text { modificaciones } \\
\text { millones COP }\end{array}$ \\
\hline Concesión & $16 / 12 / 1994-$ & $15 / 09 / 1995-$ & $01 / 01 / 2019$ & $\begin{array}{c}\$ 10.685 \\
\text { cifras agosto } \\
1994\end{array}$ & $\begin{array}{c}\$ 539.081 \text { cifras } \\
\text { diciembre } \\
2015\end{array}$ \\
\hline Vía al Mar & $20 / 10 / 2015$ & $01 / 01 / 2019$ & & 2015 \\
\hline
\end{tabular}

Fuente: Agencia Nacional de Infraestructura: https://www.ani.gov.co/proyecto/carretero/cartagena-barranquilla-21256. Elaboración: Cálculos propios. 
TABLA 7. COMPARACIÓN ENTRE LA CONCESIÓN ACTUAL DE VÍA AL MAR Y LA NUEVA 4G ENTRE CARTAGENA Y BARRANQUILLA

\begin{tabular}{|c|c|c|}
\hline $\begin{array}{l}\text { Datos Concesión Actual } \\
\text { Contrato n. } .^{\circ} 503 \text { de } 1994\end{array}$ & $\begin{array}{c}\text { Unidades /Otros Datos Contrato } \\
\text { n. }{ }^{\circ} 503 \text { de } 1994\end{array}$ & $\begin{array}{l}\text { Datos de la nueva concesión APP } \\
\text { Contrato n. }{ }^{\circ} 004 \text { de } 2014\end{array}$ \\
\hline Longitud concesionada & $93 \mathrm{Km}$ & $146.6 \mathrm{Km}$ \\
\hline Doble calzada contratada & $22 \mathrm{Km}$ & $36.70 \mathrm{Km}$ \\
\hline Rehabilitación & $4,74 \mathrm{Km}$ & 0 \\
\hline $\begin{array}{l}\text { Mejoramiento, Operación } \\
\text { y Mantenimiento }\end{array}$ & 0 & $88,48 \mathrm{Km}$ \\
\hline Interventoría & Consorcio Insevial & MAB Ingeniería de Valor \\
\hline $\begin{array}{l}\text { Stakeholders/interesados } \\
\text { en el proyecto }\end{array}$ & $\begin{array}{l}\text { Instituto Nacional de Vías - Invías } \\
\text { Ministerio de Transporte Alcaldía } \\
\text { de Cartagena, Gobernación de } \\
\text { Bolívar, Alcaldía de Barranquilla, } \\
\text { Gobernación del Atlántico, } \\
\text { comunidades de ambas ciudades, } \\
\text { industria del turismo de ambas } \\
\text { ciudades, turistas }\end{array}$ & $\begin{array}{l}\text { Ministerio de Transporte Agencia } \\
\text { Nacional de Infraestructura } \\
\text { ANI Alcaldía de Cartagena, } \\
\text { Gobernación de Bolívar, Alcaldía } \\
\text { de Barranquilla, Gobernación del } \\
\text { Atlántico, comunidades de ambas } \\
\text { ciudades, industria del turismo de } \\
\text { ambas ciudades, turistas }\end{array}$ \\
\hline $\begin{array}{l}\text { Concesionario de opera- } \\
\text { ción y mantenimiento }\end{array}$ & Consorcio Vía al Mar S.A. & $\begin{array}{l}\text { Concesión Costera Cartagena } \\
\text { Barranquilla SAS }\end{array}$ \\
\hline
\end{tabular}

Fuente: Agencia Nacional de Infraestructura. Recuperado de http://www.ani.gov.co/modo-carreteras /Elaboración: Cálculos propios

Problemática Concesión actual-Contrato 503 de 1994: esta concesión de primera generación se modificó mediante un otrosí del 20 de enero de 2006, su modelo financiero, pasando de un esquema de ingreso mínimo garantizado a través del pago de peaje, a ingreso esperado por $\$ 277.000$ millones de pesos de 2005 , que se debe alcanzar el $1^{\circ}$ de enero de 2019 (ALVEAR SANín, 2008). Para ello, se adicionaron las obligaciones para las partes, modificando su Tasa Interna de Retorno - TIR a 13\% anual, este otrosí ascendió a $\$ 19.804$ millones, dentro de los cuales se cuentan $\$ 5.545$ millones de intereses incluidos en el CAPEX del proyecto; esto ocasionó que el valor de las modificaciones ascendiera a $\$ 323.352$ millones a precios de agosto de 2010. Estas modificaciones tienen su respaldo en el Conpes 3666 del 25 de junio de 2010, el cual modificó el plan de inversiones y el alcance físico del contrato, apalancado en vigencias futuras.

Sin embargo, el Ministerio de Transporte (AlVEAR SANín, 2008) en un estudio realizado en el año 2008, había evidenciado que en la primera generación de concesiones, y en particular esta, sus ingresos fueron inferiores a las proyecciones de tráfico garantizado, lo que babía significado reclamaciones contra el gobierno en 2002-2006 por valor de $\$ 21.747$ millones para esta concesión, debido a la activación de las garantías durante ese período.

Por tanto, conforme a un informe de auditoría de vigencia 2011 de la Contraloría General de la República, se evidenciaron hallazgos fiscales por valor de $\$ 38.387$ millones, entre otros aspectos, por indebido reconocimiento en el modelo financiero de las varia- 
bles Intereses, Impuesto a la Renta y Costo de Operación de Peajes (Contraloría General de la República, 2011).

Adicional 9 de 2010 y obra anillo vial de Crespo: este adicional al contrato de la concesión actual tiene por objeto la construcción de la totalidad de las obras requeridas en el Acceso a Cartagena-Anillo Vial de Crespo en doble calzada en una longitud total de $2,5 \mathrm{~km}$, el valor global de las inversiones en las obras y actividades se acordó en la suma de $\$ 323.352$ millones a cifras de 2009 y el plazo de la construcción de las obras sería de 48 meses, que culminó en septiembre de 2014. Esta obra se integrará a la concesión 4G en 2019, tal como quedó pactado en el contrato, pues esta obra hace parte de la Unidad Funcional n. ${ }^{\circ} 1$ del contrato de concesión en estudio.

Sin embargo, conforme al informe presentado por la Contraloría General de la República, (Contraloría General de la República, 2016), en el cual se dejó un hallazgo con presunta incidencia fiscal por un presunto detrimento patrimonial a las finanzas del Estado (pérdida de recursos), debido a que, en la ejecución del adicional del 9 de junio de 2010, para el desarrollo de la obra del Túnel de Crespo, que debe unirse a las obras de la concesión objeto de estudio, una entidad de Banca de Inversión hizo la revisión de los desplazamientos de la inversión de la concesión, en la cual a octubre de 2014, el concesionario se estaría beneficiando con el retraso del cronograma de las obras, pues estaría recibiendo ingresos por peajes y a la vez aborrando costos en operación y mantenimiento, que es reconocido en el modelo financiero y en el ingreso esperado, lo cual no es ventajoso para el Estado, ya que, a 1 de septiembre de 2014, el concesionario Consorcio Vía al Mar no había culminado la obra del Túnel de Crespo, y el Estado le está reconociendo un mayor valor de la inversión en términos de Valor Presente a \$37.318 millones a septiembre de 2016, con una Tasa Interna de Retorno pactada del 7,75\%, incumpliendo lo dispuesto en el Artículo 4 de la Ley 80 de 1993, pues no se estaba ejecutando de manera oportuna el objeto contratado.

De igual forma, en este mismo informe, se evidenció que en las obras del túnel sumergido de Crespo, que en 2019 deberán integrarse al proyecto 4G en estudio, la firma encargada de hacer la interventoría de las obras, autorizó la circulación de usuarios pero de manera controlada y sin entrega final de las obras, porque a septiembre de 2016 no se le había dado solución a las fisuras presentadas en la placa de supresión en los muros laterales, y los daños registrados en las losas, que a cifras de 2016 ascienden a $\$ 58.975,79$ millones. En definitiva, existe un presunto detrimento patrimonial de $\$ 96.294$ millones denunciado por la Contraloría General de la República para este proyecto.

\section{ESTUDIO DE CASO Y METODOLOGÍA APLICADA}

La evaluación ex ante de política pública empleó una metodología de investigación cualitativa y cuantitativa a partir de las siguientes estrategias, utilizando el horizonte de tiempo de 2013 hasta abril de 2017: 
a) Estimación económica del modelo financiero de la concesión vial bajo el esquema APP Cartagena-Barranquilla.

b) Comparación de la Experiencia internacional de instituciones como el Banco Mundial, el BID, portal de infraestructura IJ GLOBAL, Senado de Francia, Corte de Cuentas de Francia, la Oficina de Auditoria del Reino Unido, revistas y publicaciones especializadas en Infraestructura de Chile y EEUU, expertos investigadores en el tema; con lo establecido por la legislación colombiana, jurisprudencia de las Altas Cortes, y aquellos organismos que ejecutan la política en nuestro país como la Agencia Nacional de Infraestructura y el Departamento Nacional de Planeación.

c) Análisis de información cualitativa a través de dos softwares de análisis de datos: NVIVO y ATLAS TI ${ }^{4}$.

En cuanto al modelo financiero, se construyó de la siguiente manera:

Con los valores de la oferta económica presentada por MARIO HUERTAS (concesionario), con la cual la ANI le adjudicó el contrato objeto de la presente investigación, se hizo la estimación de los valores a pesos corrientes, para elaborar el modelo que se proyectó por el término que dura la concesión (25 años). Se tuvo en cuenta que para la proporción de capital y equity, se hizo un estimado de $80 \%$ para deuda y $20 \%$ para equity (capital), a diferencia de la aprobación de los modelos de cada uno de los contratos de concesión de cuarta generación, que son $70 \%$ deuda y $30 \%$ equity (capital), esto se hizo porque algunos de los valores económicos de tipo confidencial del concesionario no pudieron obtenerse. A partir de ahí se diseñaron varios escenarios para establecer una situación en la que se generan pasivos contingentes y donde los ingresos reales de la concesión son iguales a los ingresos que exige el contrato, modificando la comisión de consecución de capital, dándole así mayor importancia a que el equity puede provenir de la financiación de la banca multilateral. Es importante tener en cuenta que la distribución de riesgos y la valoración del pasivo contingente fueron los elementos transversales que definieron el análisis del modelo y la información que se comparó de la experiencia nacional e internacional.

Una vez estimado el modelo financiero, se hizo una valoración cualitativa y cuantitativa de los siguientes aspectos:

- Análisis de las cláusulas de la parte especial del contrato de concesión 004 de 2014 y el contrato 503 de 1994-Contratos de la concesión en estudio.

- Información estadística y normativa de los formuladores de política en materia de Concesiones Viales (legislación, Conpes, decretos reglamentarios).

4 Atlas TI y NVIVO son softwares de análisis cualitativo de datos, que permiten el procesamiento de datos numéricos y de texto, estructurados o no, tales como: entrevistas, respuestas de encuestas con preguntas abiertas, artículos, contenido de redes sociales y web, con fines investigativos, y es empleado para todo tipo de investigaciones. Recuperado de http://atlasti.com/product/what-is-atlas-ti/, y http://www. qsrinternational.com/nvivo-spanish 
- Informes de auditoría de la Contraloría General de la República del caso en estudio.

- Análisis e interpretación a partir de la elaboración de sociogramas de las cuentas de Twitter de las instituciones nacionales e internacionales de relevancia para las concesiones de cuarta generación.

- Información de organismos multilaterales (BID, Banco Mundial, Asian Development Bank).

- Información de doctrina especializada en material de infraestructura (reconocidos ingenieros de Chile, Japón, EEUu, Colombia, revistas científicas, portal IJGLOBAL, portal Infralatam del BID).

- Experiencia internacional (Oficina del Auditor Nacional del Reino Unido, Senado de Francia, Corte de Cuentas de Francia, estudios de caso del Banco Mundial).

- Jurisprudencia de Colombia en materia de Teoría de la Imprevisión y doctrina jurídica de investigadores en la materia.

\section{RESULTADOS}

\subsection{Aspectos claves que se tuvieron en cuenta de la Asignación de Riesgos para el análisis}

En el contrato de concesión bajo el esquema APP se presenta un tratamiento contable de la obligación financiera fuera del balance general y, por lo tanto, las garantías que ofrece el promotor para fondear el proyecto son los activos y los flujos de caja futuros/altos costos de transacción en proyectos, entre el $5 \%$ y el 10\% del coste total del proyecto.

La relación entre la asignación riesgo comercial y las disposiciones del Conpes 3760 de 2013 -que regula las concesiones 4G de la primera ola- revelan que se ha pactado un respaldo económico del Estado al privado en caso de que la demanda no cubra las estimaciones de tráfico presentadas por el concesionario, lo cual confirma las estadísticas mundiales aportadas por el portal IJGLOBAL en materia de infraestructura, ya que durante los años 2009-2013, de los 939 proyectos de APP en el mundo que tuvieron cierre financiero, 287 tuvieron apalancamiento del 100\%, lo que confirma la importancia del endeudamiento para el desarrollo de estos proyectos, con dos características importantes: alto apalancamiento y contratos de largo plazo. De hecho, a cifras de 2016, el porcentaje de deuda proveniente de préstamos bancarios frente al equity (capital) es bastante alto durante los años 2014-2016, siendo la ratio de la deuda frente al equity en proporción de 69:31, y en el cuarto trimestre de 2016 se estimaba en una proporción de 71:29. (IJGLOBAL, 2016).

Adicional a esto, el Conpes 3760 también dice que el pago de la adquisición de los predios que tenga que hacer el concesionario, se pueden hacer a través de la Financiera de Desarrollo Nacional, o con el desarrollo de instrumentos de capital o deuda.

Así mismo, conforme a lo aprobado en la Ley de infraestructura (Ley 1682 de 2013), el diseño jurídico de las licencias especiales tiene inconsistencias, pues lo único que procuran es garantizar la oferta vial a bajo costo en el menor tiempo posible, sin importar los costos económicos a largo plazo que estas decisiones pueden acarrear a las comunidades 
beneficiadas o afectadas con tal decisión. Lo anterior porque la redacción del Artículo 15 de la citada ley busca ese fin (HERNÁNDEZ BETANCUR, 2015).

En contraposición, la Ley 1882 de 2018 protegió los derechos de los financiadores de los contratos de concesión bajo el esquema APP, en la medida en que a las entidades que hayan prestado su dinero de buena fe se les debe retribuir su inversión. En el Artículo 20 se hizo una modificación al parágrafo 1 del Artículo 32 de la Ley 1508 de 2013, estableciendo el pago de una cláusula penal por parte del concesionario que incumpla, que en principio sería equivalente al $5 \%$ del valor del contrato.

Conforme a cifras de la interventoría del contrato en estudio, en octubre de 2016, vemos que el estado de la subcuenta de patrimonio autónomo ${ }^{5}$ se ha incrementado, pasando de $\$ 252.480^{[6]}$ millones (cifras 2012) a $\$ 294.460$ millones (cifras de 2016), en un $85,74 \%$ con respecto al valor de los giros aprobados en el contrato n. ${ }^{\circ} 004$ de 2014, y el rubro de mayor valor corresponde a la compra de predios, lo cual indica que llegará un punto en que los giros de equity podrían no ser suficientes para cubrir las necesidades del proyecto en su etapa de construcción, teniendo en cuenta que esta debe finalizar en el año $2019^{[7]}$.

Debido a los altos costos de transacción que se presentan en los proyectos desarrollados por medio de Project Finance, es posible que el concesionario no pueda cumplir con las condiciones de disponibilidad y nivel de servicio, lo cual tendría un impacto negativo, en términos de rentabilidad. Por ello, los desarrolladores del proyecto deben tener un estricto control de los costos asociados en la estructuración y además cumplir lo pactado con el Estado referente a disponibilidad y nivel de servicio, considerando que si el proyecto tiene aprobadas vigencias futuras, estas podrían disminuir por el incumplimiento del concesionario afectando los recursos proyectados.

5 Patrimonio autónomo: los diferentes actores de los contratos de concesión bajo el esquema APP se vinculan mediante el patrimonio autónomo, los aportes del concesionario se hacen con capital propio más deuda que este asume con un prestamista mediante un contrato de crédito, los aportes del Estado (intermediados por la ANI) y los ingresos por peajes y explotación comercial conforman los recursos disponibles para el proyecto. Con el patrimonio autónomo se realizan pagos tanto al concesionario como a sus contratistas, prestamistas y al interventor contratado por la ANI. Es importante señalar que el patrimonio autónomo será administrado mediante un contrato de fiducia, suscrito entre el concesionario y una entidad fiduciaria. Recuperado de http://www.banrep.gov.co/docum/Lectura_finanzas/pdf/ isi_sep_2014_reacuadro3.pdf

6 Esta cifra indexada a julio de 2016, fecha en la cual la firma de interventoría emitió el informe de avance de concesión, estaría en $\$ 6.5$ billones, para lo cual se hizo una comparación entre el IPC de julio de 2012 y el de julio de 2016, fecha de emisión del informe. Ver DANE https://www.dane.gov.co/index. php/estadisticas-por-tema/precios-y-costos/indice-de-precios-al-consumidor-ipc y http://actualicese. com/actualidad/2015/10/22/indexacion-de-valores-como-hacerlo-facilmente/

7 En cuanto al informe de interventoría con corte a octubre 31 de 2016, manifiesta que la gestión predial globalmente tiene un avance de un $63,8 \%$ en cuanto a trámites, pero solo se ha aprobado el $12,8 \%$ de los avalúos y solo el 5,7\% de los predios tienen promesa. De igual forma, se evidencia que para los 72 avalúos aprobados se tiene el presupuesto correspondiente al 50\% del total de la subcuenta de predios que su valor inicial asciende a $\$ 175.608$ millones, y con el $87,2 \%$ de los avalúos pendientes por aprobar se supere el presupuesto inicial de la subcuenta de predios en un alto porcentaje. En cuanto al informe de interventoría de junio de 2017 , se evidencia un avance de $47,23 \%$, en parte porque durante ese mes se generó una nueva línea de base en la unidad funcional 1, y por el avance del $96,24 \%$ de la unidad funcional 4 . 
La renegociación es inevitable: las más comunes son ajuste del peaje, extensión del contrato y subsidio anual por parte del gobierno al concesionario. Para XIONG y ZHANG (2014), esta figura es de ocurrencia frecuente en las APP, y en la mayoría de los casos los gobiernos indemnizan a los promotores o concesionarios por pérdidas. Además, el núcleo de los modelos de renegociación se basa en el análisis del flujo de caja, la previsión de la futura demanda de tráfico y los costos de operación y mantenimiento. En los estudios de caso, se demostró que el sector privado, por lo general, es el primero en iniciar un proceso de renegociación. Esto se debe a las expectativas no satisfechas como previsiones de tráfico o la incapacidad del gobierno para cumplir las obligaciones contractuales, como la obtención de los permisos ambientales.

En cuanto a los escenarios de renegociación tomados de la experiencia internacional, demostraron que las evaluaciones de las ofertas tuvieron asimetrías de información frente a lo que sucedió en efecto en la ejecución de esos contratos, porque el Estado solo se conforma con analizar los beneficios inmediatos del proyecto sin apreciar los riesgos de la duración de todo el contrato. En últimas, conforme a un estudio realizado por la firma Standard \& Poor's en el año 2007, en el entendido de que la fórmula de la APP, sobre todo en temas de infraestructura, era exitosa en un contexto relativo, y que dependía de muchos factores, entre otros de la adecuada definición de las obligaciones contractuales, responsabilidades y asignación de riesgos y la implementación de prácticas y políticas que permitan evitar las negociaciones extendidas entre el Estado y el Concesionario (STANDARD \& POOR'S, 2007). No obstante, Colombia ha desarrollado un sistema sofisticado de administración de pasivos contingentes que surge de las garantías ofrecidas a las concesiones de carreteras con peaje. Este sistema incluye la estimación del impacto fiscal del presupuesto de la Nación que aporta la ANI, de las garantías antes que sean otorgadas, y apartar fondos para cubrir los pagos estimados de las garantías, a través del fondo de pasivos contingentes administrado por la Fiduprevisora (Ley 448 de 1998, Ley 819 de 2003, Ley 1437 de 2011, Régimen de Contabilidad Pública expedido por la Contaduría General de la Nación), y su valoración tiene que ser aprobada por la Dirección de Crédito Público del Ministerio de Hacienda. Sin embargo, la estimación de los mismos para las concesiones APP de iniciativa pública, como es el caso de estudio, es más difícil que la de los pasivos directos, ya que la necesidad del cumplimiento puntual y el valor de los pagos son inciertos, implica hacer análisis de los supuestos que afectan el valor de los mismos, incluyendo el cálculo del costo de una garantía sobre una variable particular, como es el caso de la demanda de tráfico o, en el peor de los escenarios, podría ser el incumplimiento de varios puntos del contrato por la parte privada (Banco Mundial, 2014).

Visto desde la perspectiva de las APP (BARRETO, 2016) y teniendo en cuenta la legislación colombiana, un contrato flexible es aquel en el que las partes no tratan de evitar la renegociación y planean renegociar el precio una vez la incertidumbre se concreta. Sin embargo, la facultad de modificar ilimitadamente el contrato es propia solo de los particulares en virtud de su autonomía privada. Por ello, el Consejo de Estado ha dicho que la modificación de los contratos estatales es limitada y debe sopesarse frente a la autonomía de la voluntad propia del Estado. 
Por tanto, la flexibilización de los contratos de concesión bajo el esquema APP y, por ende, su renegociación solo es admisible en cuanto más razones de interés público estén presentes en el caso concreto (p. ej., situaciones externas como es el caso de la problemática de la Ciénaga de la Virgen). De hecho, las fórmulas de retribución y estructura tarifaria propuestas por la ANI en el modelo especial de contrato de concesión (literal a numeral 4.3) que se aplica a todos los contratos de concesión, tienen configuradas varias variables relacionadas con el CFA (aportes subcuenta unidad funcional, recaudos de peaje, ingresos por explotación comercial, índices de cumplimiento de la unidad funcional, entre otros). No obstante, deben siempre sopesarse con la estructura contractual rígida planteada por la Ley 1508 de 2012 y sus Decretos Reglamentarios, los cuales se encuentran materializados en el literal a del numeral 13.1 del modelo especial de contrato de concesión bajo el esquema APP desarrollado por la ANI, en el cual el concesionario expresamente reconoce que no serán procedentes ajustes, compensaciones, indemnizaciones o reclamos que tengan origen en esos factores.

Los contratos de 4G tienen herramientas importantes adoptadas para que se pueda financiar el programa sin recurso a la concesionaria. Sin embargo, a la fecha, muchas de las financiaciones han podido concluirse porque los riesgos que han sido asignados al concesionario tienen la potencialidad de afectar la fuente de pago y por ello los financiadores no desembolsan hasta no obtener la evidencia de la mitigación del riesgo (ABELLO GaLviS, 2018). Conforme a los criterios esbozados por el Banco Mundial (BULL, 2017), para efectos de localizar y mitigar los riesgos se deben dar 4 pasos:

- Establecer la viabilidad financiera y el retorno de la inversión del proyecto.

- Hacer análisis cualitativos y cuantitativos que permitan indexar y hacer análisis de sensibilidad de tráfico y de los peajes.

- Un análisis sombra del crédito que contempla dos vías: el análisis del riesgo de tráfico con el análisis de la posición del crédito del proyecto. Estos targets son: la ratio que cubre el servicio de la deuda (DSCR) y la ratio que cubre el valor del crédito (LLCR). El primero corresponde a la capacidad que tiene el proyecto para cubrir con sus obligaciones, y el segundo corresponde a un indicador orientado a futuro, que permite evidenciar la capacidad del proyecto de repago de sus deudas por fuera del balance general. Un proyecto con una sólida posición de crédito puede ser valorado siempre y cuando los targets de sus ratios financieros estén presentes a lo largo de la vida del proyecto. Un proyecto con una fuerte posición de crédito (fuerte financiación) presenta una mayor flexibilidad para manejar el riesgo de tráfico, en comparación con otro que no lo tenga.

- Establecer y mitigar los riesgos, que pueden darse a través de 4 modelos: alto riesgo de tráfico y baja viabilidad financiera (modelos de riesgo retención), en el cual el Estado retiene la mayoría de los riesgos significativos; modelo de riesgo compartido, en el cual existe alto riesgo de tráfico y alta viabilidad financiera, tanto el Estado como el concesionario comparten los riesgos, y se da el modelo de ingreso mínimo garantizado y mecanismos de compartir ganancias. 
- Riesgo de tráfico razonable y baja viabilidad financiera, denominado por su término en inglés modelo de risk injection, como es el caso de los peajes sombra. Esta figura puede emplearse para separar el riesgo de tráfico de otros riesgos a fin de prevenir al sector privado de depender únicamente de los ingresos por peajes.

- Riesgo de tráfico razonable y alta viabilidad financiera, es básicamente un modelo de riesgo-transferencia, en el cual se transfiere todo al usuario final y se dan términos contractuales flexibles. Este modelo es más apropiado para proyectos que ofrecen bajo riesgo y alta rentabilidad. Los gobiernos deben adoptar medidas de debida diligencia, para asegurar riesgos de tráfico razonables a fin de evitar la bancarrota o la renegociación, con el fin de que los activos de la concesión sean bien valorados para mitigar las ganancias excesivas para el sector privado.

\subsection{Resultados en detalle de la experiencia internacional}

La mayor experiencia internacional en esquemas APP se encuentra en la Unión Europea, donde en los últimos 15 años se han firmado más de 1.000 contratos de este tipo que representan una inversión cercana a los 200.000 millones de euros en sectores como educación, salud, defensa, justicia y transporte a través de las diferentes modalidades de APP. Dentro de esta experiencia, el modelo más avanzado es el desarrollado en el Reino Unido, denominado Private Finance Initiative (PFI), que representa cerca del 58\% del total de la inversión materializada en este tipo de contratos (Departamento Nacional de Planeación).

En lo atinente a la experiencia comparada, al analizar este acápite de los ingresos derivados de las tarifas, se puede decir que para garantizarse una verdadera reducción de los riesgos, se debe procurar que las asimetrías de información entre el Estado y el contratista, y las simetrías de competencia que puedan existir entre estos actores, se compensen, de suerte tal que permita en una segunda fase si hay una eventual renegociación, haya un equilibrio en las obligaciones y que no exista un beneficio económico superior de una parte con respecto a la otra (SAUSSIER, 2011).

Por un lado, existen serias deficiencias en los documentos de evaluación previa, ya que esta se constituye en un documento técnico previo a la realización de un proyecto de APP denominado en Francia PPP (Partenariat Public Privé), pero no a una mejor estructura jurídica del contrato de asociación que sea de utilidad a la entidad pública. En muchas ocasiones, las bases de estas evaluaciones son desconocidas para la entidad pública. Esto demuestra una dependencia de la entidad pública por el maestro de obra, y la parte privada encargada de la evaluación, generando una asimetría de la información.

Por otra parte, conforme a lo dicho por el Senado de Francia (2013-2014), se evidencia para el caso de los contratos de asociación que, en el análisis de las evaluaciones previas realizadas por el Estado, frente a los beneficios transversales implícitos a ese contrato y la ausencia de información aportada por el privado relativa a la sostenibilidad presupuestal de esos compromisos, demuestran que la persona pública (entidad estatal) solo se conforma con analizar los beneficios inmediatos del proyecto sin apreciar los riesgos de la duración de todo el contrato. 
De igual forma, la Corte de Cuentas de Francia manifestó las dificultades, para establecer el balance económico del contrato, resultante de la complejidad de los modelos financieros utilizados que deben ajustarse al ámbito de la ejecución del contrato, ya que la evaluación a largo plazo de un contrato mal negociado desde el origen será condicionado a la celebración de modificatorios y/o cláusulas adicionales. De hecho, la organización MAPPP (Misión de Apoyo de las Asociaciones Público-Privadas) de Francia reveló que el 97\% de los contratos APP son renegociados principalmente por ajustes de los términos financieros y del objeto de la ejecución del contrato que fueron pactados en la etapa precontractual (Cour des comptes, 2015).

En cuanto a lo que ha estipulado el Banco Mundial frente a este tipo de proyectos, ha dicho que en algunas circunstancias la capacidad de la APP para crear incentivos para mejorar el mantenimiento será limitada. En las APP de pago de usuario, y en las APP pagadas por el gobierno se necesita un monitoreo eficiente a través de un buen diseño contractual si se quiere lograr el beneficio potencial de un mejor mantenimiento. En el caso de estudio del proyecto de Bangkok Sky-train, se hizo la acotación de que la estimación de tráfico en el sector transporte está caracterizada por grandes errores y que el margen de error de la estimación de tráfico está entre el 50\% y el 70\%.

Con las estimaciones de tráfico de este caso, se proyectó que la corporación del Sistema de Transporte de Bangkok BTSC podría recuperar su inversión en los primeros 10 años al menos con un $16 \%$ de TIR (Tasa Interna de Retorno), para un costo total del proyecto de 1,4 billones de dólares. En las predicciones de tráfico, el proyecto fue aprobado con una estimación de 600.000 viajes por día en 1992, sin embargo, en 2006 solo había alcanzado los 380.000 viajes por día y para 2013 apenas llegaba al 30\% de las predicciones iniciales, lo que condujo a la empresa a una cesación de pagos, y acogiéndose a la ley de insolvencia convirtió gran parte de la deuda a equity bajando la ratio de apalancamiento a menos de 0:3:1 y una empresa BTSGIF compró gran parte del BTSC. A pesar de que su funcionalidad estuvo comprobada por la reducción de la congestión en el centro de Bangkok, sus inadecuadas predicciones de tráfico hicieron que el proyecto no fuera exitoso para los inversionistas y financieros (Banco Mundial , 2014).

\subsection{Resultados de la estimación del modelo financiero}

Para esta investigación, teniendo en cuenta la oferta económica aprobada y publicada en la página web de la ANI, se hizo una estimación del modelo financiero a través de un flujo de caja a precios corrientes, con los datos que se pudieron obtener de la ANI, la cual fue indexada para nuestro estudio de caso, para efectos del análisis del CAPEX (inversión) y OPEX (operación y mantenimiento), costo promedio de la estructura de capital, algunos datos de la concesión actual, y otras variables macroeconómicas de financiación para hacer las proyecciones necesarias y hacer el análisis relativo, que está por mensualidades conforme a la duración de la concesión. 
Los datos más importantes del modelo financiero pueden resumirse en lo siguiente:

GRÁFICA 2. DATOS DE ENTRADA PARA LA ESTIMACIÓN DEL MODELO FINANCIERO

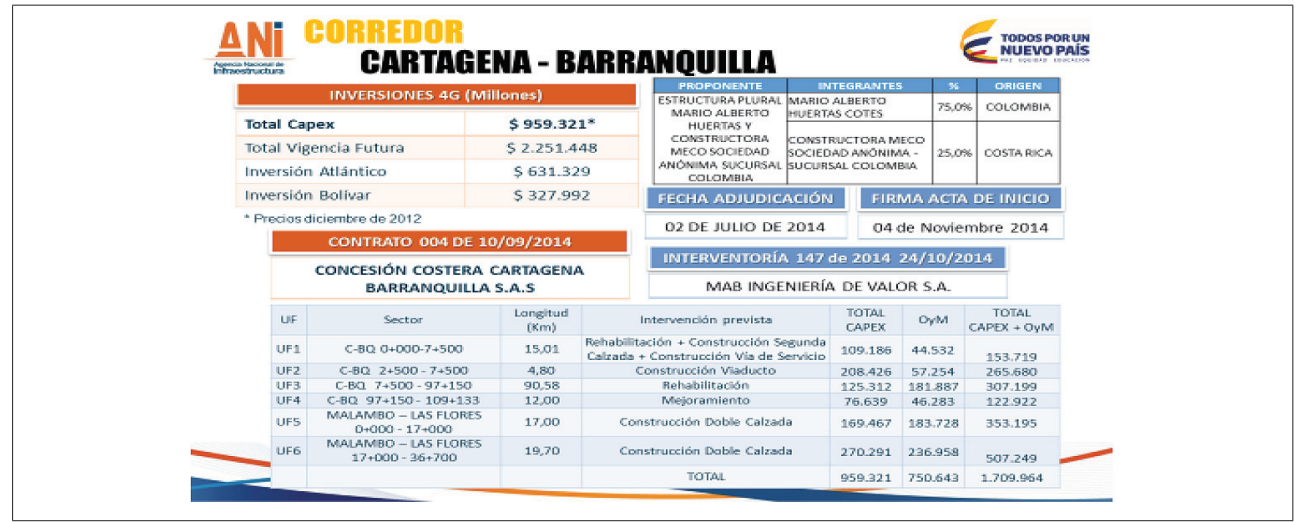

Fuente: Agencia Nacional de Infraestructura. Recuperado de http://www.ani.gov.co

En esta investigación se plantearon dos hipótesis, de las cuales la primera arrojó una alta probabilidad de generación de pasivos contingentes para la ejecución del contrato de concesión bajo el esquema APP expuesto en esta investigación, que en cierto punto presentan dificultades para la estimación de sus costos, y el pago de los mismos por parte del privado es incierto.

TABLA 8. VALOR PRESENTE NETO Y TASA INTERNA DE RETORNO

DEL PROYECTO CONTRATO 004 DE 2014 APP EN MILLONES (\$ DE 2016)

\begin{tabular}{|l|c|}
\hline Valor de la inversión CAPEX & $\$ 1,31$ billones \\
\hline Valor presente neto concesión modelo (\$2016) & $\$ 224.366$ \\
\hline Tasa interna de retorno & $14,71 \%$ \\
\hline $\begin{array}{l}\text { Ingreso Esperado Concesión Contrato Aprobada anexo técnico } \\
\text { (pesos de \$2005) }\end{array}$ & $\$ 269.000$ \\
\hline Comisión de consecución de capital & $1,00 \%$ \\
\hline $\begin{array}{l}\text { Pasivo contingente estimado (Diferencia entre el valor presente neto } \\
\text { concesión modelo y el ingreso esperado aprobado en el contrato) }\end{array}$ & $\$ 44.633$ \\
\hline Tiempo de la concesión (construcción y operación) & 25 años \\
\hline Periodo de tiempo donde se hace la inversión en la concesión (48 meses) & $\begin{array}{c}\text { Enero 2016 a diciembre } \\
\text { de } 2019\end{array}$ \\
\hline
\end{tabular}

Fuente: ANI Apéndice técnico APP n. ${ }^{\circ} 004$ de 2014 - Cálculos propios con fundamento en el Contrato 503 de 1994 y el Contrato n. ${ }^{\circ} 004$ de 2014 establecidos en el modelo financiero (se tomaron los valores de la oferta económica aprobada al concesionario y las cifras se trajeron a valor presente para poder hacer las estimaciones).

8 Esto se puede encontrar en el literal (c) i numeral 3.8 Anexo 1 Contrato 004 de 2014, parte especial. 
Por tanto, se planteó un nuevo escenario, donde queda contemplada la renegociación.

Lo anterior, debido a que el sistema de Project Finance no puede predecir con exactitud las variables que pueden influir en el largo plazo en la ejecución de la concesión bajo el esquema APP, en particular para el caso de los costos asociados al proyecto, y no refleja la realidad del negocio propuesto; es decir, el método de flujo de caja que emana de la metodología de Project Finance y que toma el método del comparador público privado, utilizado en la estructuración de negocios de las concesiones APP, no está en capacidad de establecer criterios de contingencia ante la ocurrencia de los riesgos asociados al proyecto, generando eventualmente mayores costos. Es importante tener en cuenta que, desde el punto de vista financiero, la recuperación de la inversión sería en el año 14 del proyecto conforme a la estimación del modelo presentado.

De igual forma, llama la atención que, después de firmado el Conpes 3760 , son pocas las concesiones que han logrado cierre financiero definitivo, y dieciocho han sido postergadas para 2018, las certificaciones de esos cierres, son en su mayoría comandadas por Goldman Sachs, el banco Sumitomo de Japón ${ }^{9}$, la Corporación de Crédito Agrícola de Francia y la IFC del Banco Mundial, que junto a otras corporaciones del mundo tomaron el $55 \%$ de la financiación acreditada para las vías de cuarta generación. El porcentaje restante se encuentra concentrado principalmente en el Banco de Bogotá, Bancolombia y Davivienda, con un nivel de $\$ 7,6$ billones de pesos en el apalancamiento de los proyectos (TRIGOS, 2017).

Se podría resumir que los primeros seis financiadores de las vías de cuarta generación, entre nacionales y foráneos, concentran 16,5 billones -un estimado del 66\%-de los compromisos certificados -sin cierre de caja definitivo- para apalancar tales vías. Sumado a eso, las constructoras en las vías $4 \mathrm{G}$ representan un verdadero enjambre de negocios: en unos proyectos son rivales y en otros socios; en otros, los 'rivales' son interventores de sus otros socios y, en esa marejada de intereses, aparecen diez firmas que se hacen a la participación del 60\% de las concesiones. La fila a 2016 está encabezada por Solarte con siete, Cóndor con seis y Episol con cinco, seguidos de unas con menores participaciones como Sacyr, Odinsa, Conecol, Colpatria, Hidalgo, OHL y Mario Huertas, quien es el constructor del caso de estudio. El caso se hace peor en el control total sobre los proyectos: ocho firmas se hacen al manejo absoluto de 18 concesiones, y con ellas a la renta anual de por lo menos 55 peajes (TRIGOS, 2017).

Esa concentración tiende a confundirse, pues existen preacuerdos entre las firmas para que una vez ganada la licitación se cedan partes a otras constructoras o se intercambien participaciones y se ajusten negocios, una medida poco ortodoxa en la libertad de mercado. Esto ha producido que hoy las firmas extranjeras, además del control que

9 Conforme a lo dicho por la Contraloría General en el informe de Actuación Especial a REFICAR vigencia 2016, páginas 16 a 24, este Banco participó como Banco Agente en parte de las negociaciones de la estructuración de un crédito a Reficar, dentro del modelo de estructuración con la Agencia de Créditos de Exportación ECA, y formó parte del entramado relacionado con el negocio entre Reficar y el Banco creado en Suiza con Ecopetrol, denominado Ecopetrol Capital AG. 
tienen a través de la banca en el financiamiento, logren hacerse con proyectos hasta por 16 billones de pesos, una cuarta parte de lo que podría costar todo el ciclo 4G. Estamos ante el mismo modelo de inversión extranjera en el que se prioriza la rentabilidad de los capitales foráneos (TRIGOS, 2017).

Ahora bien, al estimar la ejecución del contrato de concesión bajo el esquema APP, más allá de los esfuerzos generados en la legislación de las APP, y en particular las disposiciones establecidas en el Artículo 19 de la Ley 1682 de 2013 (Ley de Infraestructura) para el mejoramiento de los trámites derivados de los riesgos prediales y ambientales, este contrato implica una atipicidad única, que se traduce en la aprobación de ciertas condiciones que permitan llegar a un valor en la oferta económica aprobada, pero que no garantiza que en el futuro esas condiciones del contrato permanezcan intactas, y es muy probable que las estimaciones fallen y generen una reprogramación de inversiones, debido a la volatilidad de los factores.

De igual forma, los riesgos comerciales más álgidos, en el caso de los peajes, cuando el concesionario no alcanza los ingresos esperados por recaudo, son asumidos por el Estado representado por la Agencia Nacional de Infraestructura-ANI, como lo establece el anexo técnico del contrato y el Conpes 3760 de 2013, generando en cierta medida un incentivo para una renegociación de los términos del contrato que sería desventajosa para el Estado, a pesar de los límites impuestos por la Ley 1508 de 2012, y que el riesgo predial y el riesgo de construcción están compartidos entre el concesionario y el Estado.

Sin embargo, se evidencia que los períodos de estructuración (prefactibilidad) de los proyectos de concesión bajo el esquema APP son bastante cortos $y$, por tanto, al igual que en la experiencia internacional analizada (Francia, Inglaterra, Estados Unidos), es muy probable que esos proyectos no se ejecuten a tiempo. De igual forma, el pago asociado a la unidad funcional es bastante rígido, porque esas unidades funcionales involucran riesgos como la compra de predios, que como se vio en este caso, están presentando retrasos.

De hecho, y teniendo en cuenta un pronunciamiento reciente de la Sección Tercera del Consejo de Estado, Sentencia 21990 de 2012 (Consejo de Estado, Sección Tercera. Sentencia 21990, 2012), se le da un respaldo tácito a la aplicación de esta premisa expuesta en el apartado anterior, al sostener la tesis que la denominada "Teoría de la imprevisión"10 implica que la administración tiene el deber de auxiliar al contratista mediante una compensación o de indemnizarlo de acuerdo con los requisitos señalados en esta Sentencia.

No obstante, al establecerse en la Ley 1508 de 2012 que el contrato de concesión que tipificaba la Ley 80 de 1993 queda incluido dentro del concepto de Asociación Público Privada, y que el pago se hará de aquí en adelante por disponibilidad y por unidad funcional (Artículo 4 Decreto 1467 de 2012), queda comprobado que los alcances

10 La teoría de la imprevisión se define como: "... sujeciones materiales imprevistas", que involucran circunstancias no imputables al Estado y externas al contrato, pero con incidencia en él. En todos estos eventos surge la obligación de la administración contratante de auxiliar al contratista colaborador mediante una compensación -llevarlo basta el punto de no pérdida-o nace el deber de indemnizarlo integralmente, según el caso y si se cumplen los requisitos señalados para cada figura..." (destacado fuera de texto). 
progresivos fueron eliminados en el contrato de concesión bajo la modalidad APP, los alcances de cada proyecto corresponden a las necesidades de infraestructura para los 25 años que dura la concesión. Lo anterior, debido a que el Estado, en el pasado modelo, una vez se hacían los alcances progresivos en las inversiones, comenzaba a revisar los presupuestos, los diseños, cuando el concesionario no cumplía con las condiciones exigidas por la jurisprudencia en temas del ingreso esperado por demanda de tráfico, y al imponer cambios, compartía el riesgo con el concesionario, cuando este último debía asumirlo al 100\%, trayendo como consecuencia el incremento de los costos de la obra.

Así mismo, lo que puede evidenciarse de la jurisprudencia del Consejo de Estado desde 1996-2010 es que se ha apartado de la teoría financiera, puesto que en la mayoría de los casos el Estado se ve abocado a pagar indemnización al concesionario, debido a que asume una posición contraria a la teoría financiera, teoría que afirma que los riesgos técnicos deben ser asumidos por el concesionario y que no toda variación de la situación del contrato otorga validez a la teoría de la imprevisión. Así mismo, el órgano de cierre de lo Contencioso Administrativo atribuye a la Teoría de la Imprevisión circunstancias que involucran riesgos propios del negocio y que debieron ser previstas y asumidas, en la mayoría de los casos, por el concesionario (GÓMEZ, 2006, p. 78). Es poco probable que con el modelo propuesto por las Asociaciones Público Privadas cambie un poco.

Por tanto, el contrato de concesión bajo el esquema APP, visto desde la perspectiva de la Ley 1508 de 2012, en términos generales presenta que el riesgo de construcción en su gran mayoría lo asume el concesionario y el riesgo comercial lo asume el Estado. Sin embargo, conforme a lo planteado con la experiencia internacional presentada en este trabajo, se evidencia que en esos países, cuando el concesionario no llegaba al ingreso esperado establecido en el contrato, el Estado se veía abocado a una renegociación y por tanto el riesgo de mercado, en últimas, lo asume el Estado, situación que fue replicada en Colombia a partir de las disposiciones consagradas en el Conpes 3760 de 2013.

En consecuencia, debe disminuirse la TIR, cambiando las condiciones del crédito, aumentando la comisión de consecución de capital subiendo del 1\% al 8,15\%, situación que asume el concesionario y que le da una mayor importancia a la banca de inversión encargada de proveer los fondos equity al concesionario, conforme a los criterios de estructuración del Departamento Nacional de Planeación, puesto que la banca incurre en mayores riesgos, exigiendo al concesionario un retorno mayor en términos de deuda (Departamento Nacional de Planeación, 2014), que implica en cierta medida hacer una renegociación entre el Estado y el concesionario, utilizando los criterios que sean más ventajosos para la Nación, sin afectar las demás variables, tales como el CAPEX, el OPEX y los ingresos, considerando que hay una sobreestimación de la demanda del contrato actual 503 de 1994 y que se vería replicado en el contrato 004 de 2014, que es la concesión APP en estudio. Esta alternativa le permitirá al concesionario ser más eficiente en el uso de los recursos.

La hipótesis 2 puede resumirse en la tabla 9. 
TABLA 9. NUEVO ESCENARIO PARA MITIGAR LOS PASIVOS CONTINGENTES

\begin{tabular}{|l|c|}
\hline \multicolumn{1}{|c|}{ Datos financieros } & Valor \\
\hline Valor de la inversión capex & $\$ 1,3$ billones \\
\hline TIR (tasa interna de retorno) & $13,313 \%$ \\
\hline Comisión de consecución de capital & $8,15 \%$ \\
\hline Valor presente neto concesión & $\$ 269.000$ millones \\
\hline Ingresos esperados concesión contrato APP & $\$ 269.000$ millones \\
\hline $\begin{array}{l}\text { Tiempo de la concesión (construcción y operación) } \\
\text { Periodo de tiempo donde se hace la inversión de } \\
\text { recursos en la concesión (48 meses) }\end{array}$ & 25 años \\
\hline
\end{tabular}

Fuente: Datos de la estimación del modelo financiero. Elaboración: Cálculos propios.

\section{RECOMENDACIONES}

1. Es necesaria la utilización de indicadores adicionales a los propuestos en la Ley 1508 de 2012 de eficiencia o de rotación de activos para analizar a profundidad el grado de endeudamiento del concesionario. De igual forma, los límites de esos indicadores no deben ser valores fijos, pues deben comprender elementos de manera integral, incluyendo el tipo de proyecto y sector económico involucrado (VILLARREAL, 2016).

2. De igual forma, debe evaluarse la adopción de mecanismos que minimicen el riesgo de generar asimetrías de información, en el cual el Estado-ANI- no posee la totalidad de la información del modelo económico del concesionario, lo cual afecta su flujo de caja y su costo de oportunidad, que debe implementarse en la ejecución de los proyectos de cuarta generación de segunda y tercera ola, que todavía se encuentran en etapa de prefactibilidad y factibilidad, lo cual implica un trabajo en conjunto con el Departamento Nacional de Planeación.

3. Frente a nuestro estudio de caso se debe bajar la Tasa Interna de Retorno (TIR), a fin de garantizar que no se presenten los pasivos contingentes. Lo anterior, debido a que se presentaron externalidades en la obtención de licencias ambientales completas que generaron el desplazamiento de las inversiones.

4. Conforme a información entregada por la Financiera del Desarrollo Nacional en noviembre de 2016, se ha llegado a la conclusión que es más fácil financiar un programa más distribuido en el tiempo, y por tanto se deben ampliar las fuentes de financiación internacionales a fin de lograr una mejor ejecución de los proyectos y, sobre todo, los cierres financieros con una mayor celeridad (Financiera de Desarrollo Nacional, 2016).

5. Debido a las últimas denuncias de corrupción en megaobras, como es el caso de Odebrecht y el proyecto de la Refinería de Cartagena, Reficar, se evidencia que, al 
igual que en estos casos, las concesiones viales bajo el esquema APP son proyectos con estructuras de financiación complejas y con un alto riesgo de que los plazos impuestos y los presupuestos no se cumplan. Por tanto, estos modelos financieros funcionan siempre y cuando el costo de la deuda de los créditos necesario para cubrir las obras, sea inferior a los rendimientos o ganancias que obtenga eventualmente el negocio de la concesión como tal (ingresos por peajes) (ACOSTA, 2016).

6. En consecuencia, la Financiera de Desarrollo Nacional debe buscar mecanismos rigurosos y objetivos para el otorgamiento de créditos y tener mayor participación en la formulación de los Conpes, a fin de que no le toque respaldar financieramente en todos los casos a los concesionarios que se descuadren en presupuesto o plazo mediante créditos, cuando no se hayan resuelto desde antes las asimetrías de información entre el Estado y el concesionario, que tanto pueden perjudicar al Estado, una vez ejecutadas las obras; para que no se presenten situaciones como las ocurridas con la empresa Navelena, cuyo accionista mayoritario era la polémica firma Odebrecht, que era la encargada de recuperar la navegabilidad del río Magdalena, y por sus problemas financieros y la situación del crédito del Banco Agrario le fue declarada la caducidad del Contrato 001 de 2014, contrato de concesión bajo el esquema APP.

7. Al incorporar de manera adecuada los límites a la aplicación de la flexibilidad y a la facultad de renegociar y modificar el contrato APP, se deben buscar mecanismos jurídicos de acercamiento entre los contratos estatales y contratos especiales en una categoría denominada "compras públicas y adjudicación", que incluya los contratos de concesión bajo el esquema APP, aplicando la flexibilidad de manera restringida, evaluando las razones de interés público y las externalidades que comprometan la normal ejecución del contrato (BARRETO, 2016).

8. Adoptar medidas de mitigación y compensación, en particular con lo que está ocurriendo con el tema del viaducto de la Ciénaga de la Virgen, tomando en consideración lo que ocurrió en la concesión vigente en la Vía al Mar, para que en esta contingencia no se presenten situaciones similares, sobre todo ahora que su construcción está próxima a finalizar.

9. Adoptar medidas frente a los posibles desfases que se presenten en los niveles de tráfico del proyecto, teniendo en cuenta que la economía está en un proceso de desaceleración, y es poco probable que los fondos de contingencias del Ministerio de Hacienda sean suficientes para cubrir las necesidades de este y de todos los proyectos en curso y los que se encuentran en etapa de estructuración. En consecuencia, se deben generar alertas al comportamiento del ingreso de tráfico que evite convertir los pasivos contingentes en exigibles (Anónimo, 2016).

\section{BIBLIOGRAFÍA}

Agencia Nacional de Infraestructura. Cuarta generación de concesiones viales Proyecto Vía al Mar y Circunvalar de la Prosperidad, Recuperado de http://www.ani.gov.co/CMS/media/fil e/Cartagena \%20 Barranquilla.pdf 
Agencia Nacional de Infraestructura. Informe de Gestión Especial vigencia 2012. Bogotá, pp. 1-38.

Agencia Nacional de Infraestructura (marzo 11 de 2014). El modelo APP en desarrollo de infraestructuras, en Primer Seminario Networking Arquitectura-Ciudad. Bogotá Universidad Javeriana. Recuperado de http://www.oficinascomerciales.es/icex/cda/controller/pa geOfecom es/0,5310,5280449_5300024_5286817_4739538_CO,00.html

Agencia Nacional de Infraestructura (marzo 5 de 2013). Proyecto Vía al Mar y Circunvalar de la Prosperidad. Estudios en etapa de prefactibilidad. Apéndice 1: Parte especial, p. 63.

Agencia Nacional de Infraestructura, Proyectos Adjudicados 2014. Presentación en Power Point.

(Página consultada el 26 de mayo de 2016). Recuperado de http://ani.gov.co/sites/default/ file s/u246/proyectos_adjudicados_2014.pptx

Agencia Nacional de Infraestructura [ANI_Colombia] (20 de junio de 2016). Sociogramas elaborados con los tuits recuperados de la cuenta de twitter. Recuperado de https://twitter.com/ANI_Colombia

Agencia Nacional de Infraestructura. [Agencia Nacional de Infraestructura-ANI] (20 de junio de 2016). Análisis de conglomerados elaborado a partir de Ncapture de Nvivo de la página de Facebook. Recuperado de Facebook https://www.facebook.com/AgenciaNac ionaldeInfraestructura/?fref =ts

Agencia Nacional de Infraestructura. Gobierno Nacional inaugura el Anillo Vial de Crespo en Cartagena. (Página consultada el 20 de junio de 2016). Recuperado de https://www.youtube .com/ watch? $=$ =-Lozz6a7CJY

Autopistas de la prosperidad (2013). (Página consultada el 26 de mayo), Recuperado de http:// www.autopistasprosperidad.com/proyecto.php

Agencia Nacional de Contratación. Guía para verificar la capacidad residual del proponente en los procesos de contratación pública, pp. 1-18 (Página consultada entre el 14 de marzo y el 27 de abril de 2014). Recuperado de http://www.colombiacompra.gov.co/sites/def ault/files/manuales/201 40425 guiacapacidadresidual.pdf

AlbORTA, G. (2011). Asociaciones público-privadas para la prestación de servicios una visión bacia el futuro. Banco Interamericano de Desarrollo.

Albújar, A. (2010). El Project Finance: una técnica para viabilizar proyectos de infraestructura. Lima, Universidad ESAN (Serie Documentos de Trabajo n. ${ }^{\circ} 27$ ).

AlVEAR, JOSÉ (2008). Historia del transporte y la infraestructura en Colombia (1492-2007). Ministerio de Transporte. Bogotá.

ANDRADE, L. F. (2012). Cuarta generación de concesiones en Colombia. Agencia Nacional de Infraestructura, recuperado de http://www.ani.gov.co/CMS/media/file/Cuarta\%20 Generacion\%20de\%20 Concesiones\%20Luis\%20Fernando\%20Andrade\%20Moreno.pdf

Anónimo (octubre 4 de 2012). "Concesiones viales de cuarta generación para Colombia", en Agencia de noticias UN, Recuperado de http://www.agenciadenoticias.unal. edu.co/ndetalle/article/ concesiones-viales-de-cuarta-generacion-para-colombia.html

Anónimo (2016). "Tres proyectos de vías $4 \mathrm{G}$ ya tienen cierre financiero", en Dataifx (página consultada el 28 de mayo). Recuperado de http://www.dataifx.com/n oticias/macroeconomia/ articulo-22931-tres-proyecto-de-vias-4g-ya-tienen-cierre-financiero

Anónimo (2016). "Bancolombia ha financiado \$1,2 billones de proyectos viales 4G", en Revista Portafolio (página consultada el 1 de agosto). Recuperado de http://www.portafolio.co/economia/infraestructura/bancolombia-ha-financiado-billones-de-proyectos-viales-4g-499237. 
Anónimo (2016). "Cómo van las vías de 4G en Colombia", en El Tiempo (página consultada el 1 de agosto). Recuperado de http://www.eltiempo.com/economia/sectores/como-van-las-vias-4gen-colombia/16648492.

Anónimo (2016). "La plata para las vías: infraestructura de cuarta generación", en Revista Semana (página consultada el 1 de agosto). Recuperado de http://www.semana.com/econom ia/articulo/ vias-4g-los-recursos-para-vias-de-cuarta-generacion-estan-asegurados $/ 481150$

Anónimo (noviembre de 2013). "La $4 G$ necesita ajustes" en Especial de Infraestructura, Revista Dinero, p. 15. Anónimo (noviembre 2013). "Y dónde está la plata", en Especial de Infraestructura Revista Dinero, pp. 18-19.

Anónimo (noviembre de 2013). "El eslabón que falta", en Especial de Infraestructura Revista Dinero, p. 23.

Anónimo (1 de febrero de 2013). "Arranca contratación de obras viales concesionadas de cuarta generación", en El Espectador, recuperado de http://www.elespectador .com/noticias/nacional/ articulo-402458-arranca-contratacion-de-obras-viales-concesionadas-de-cuarta-gen

Anónimo (17 de mayo de 2013). "Pasos de gigante", en Revista Dinero. Edición 421.

Anónimo (2013). "Santo Remedio?", en Revista Dinero (página consultada el 2 de abril), Recuperado de http://www.dinero.com/edicion-impresa/pais/articulo/santo-remedio/152821

Anónimo (2014). "Cuestión de infraestructura", en El Espectador (página consultada el 27 de abril). Recuperado de http://www.elespectador.com/opinion/editorial/cuestion-de-infraestructuraarticulo- 488302

Anónimo (2014). "La historia íntima de las 4G", en El Espectador (página consultada el 4 de mayo). Recuperado de http://www.elespectador.com/noticias/economia/historia-intima-de-viasde-4g-articulo-490314

Anónimo (2016). "Lento arranque de las vías 4G", en El Espectador (página consultada el 1 de abril). Recuperado de http://www.dinero.com/edicion-impresa/pais/articulo/cierres-financieros-en-ellento-arranque-de-las-vias-4g/221912?utm_source=semana.com\&utm_me dium=referral\&utm_ campaign=otras-publicaciones-footer

Anónimo (2016). "El primer traspiés en las carreteras 4G", en La Silla Vacía (página consultada el 4 de mayo). Recuperado de htttp://lasillavacia.com/historia/el-primer-traspi-s-de-las-carreteras4g-55684\#

Anónimo (2016). "Adjudicada a Huertas-Meco concesión de Vía al Mar", en El Heraldo (página consultada el 14 de mayo). Recuperado de http://www.elheraldo.co/naci onal/adjudicadahuertas-meco-concesion-de-al-mar-158082

Anónimo (2016). "Errores en la construcción del anillo vial de Crespo Cartagena”, en El Universal (página consultada el 15 de mayo). Recuperado de http://www.eltiempo.com/colombia/otrasciudades/errores-en-la-construccion-del-anillo-vial-de-crespo-cartagena/16593570

Anónimo (2016). "Gremios lanzan 8 alertas sobre circunvalar de la prosperidad", en El Heraldo (página consultada el 28 de mayo. Recuperado de http://www.elheraldo.co/local/gremioslanzan-8-alertas-sobre-circunvalar-de-la-prosperidad-253742

Anónimo (2016). "Contratista dice estar 'atado de manos' si la ANI no aprueba cambios", en El Heraldo (página consultada el 28 de mayo). Recuperado de http://www.elheraldo.co/local/contratista-diceestar-atado-de-manos-si-ani-no-aprueba-cambios-253971 
Anónimo (2016). "Cartagena-Barranquilla Highway", en IJGLOBAL (página consultada el 10 de agosto). Recuperado de https://ijglobal.com/data/transaction/26333

Anónimo (2016). ¿Aprendió Colombia a hacer concesiones de infraestructura? (página consultada el 16 de septiembre). Recuperado de http://www.dinero.com/edicion-impresa/negocios/ articulo/aprendio-colombia-a-hacer-concesiones-de-infraestructura/231872

Anónimo (2016). Hueco fiscal complica más cierres 4G: Cemex Colombia (página consultada el 16 de septiembre). Recuperado de http://www.dinero.com/edicion-impresa/negocios/articulo/huecofiscal-complica-mas-cierres-de-4g-cemex-colombia/231873

Anónimo (2017). El futuro de las $4 \mathrm{G}$ tras el escándalo de Odebrecbt (página consultada el 26 de febrero). Recuperado de http://www.dinero.com/edicion-impresa/caratula/articulo/que-pasara-conlas-4g-tras-escandalo-de-odebrecht-en-colombia/241530

Asian Development Bank et al. (2016). "The APMG Public-Private Partnership (PPP). Certification Guide". Washington. Capítulo 3.

Banco Mundial (2016). Matrix of Risk Distribution-Roads. (Página consultada el 3 de agosto). Recuperado de https://ppp.worldbank.org/public-private-partnership/sites/ppp.worldbank.org/f iles/ppp_testdumb/documents/roadriskmatrix_1.pdf

Banco Mundial (2016). Informe Doing Business. Washington, 10. ${ }^{\text {a ed. }}$

Banco Mundial (2015). Report on Recommended PPP contractual provision. Edition. Washington.

Banco Mundial (2015). Disclosure in Public-Private Partnerships: Good Practice Cases. Report august, Washington.

Banco Mundial (2015). Orientación técnica para la divulgación de información sistemática y proactiva antes y después de las adquisiciones. Washington.

Banco Mundial (2015). H1, Global Public Private Partnership update. Public Private Partnership base de datos actualizada al 2015.

Banco Mundial (2015). PPI actualización global. Base de datos actualizada al 2015.

Banco Mundial (2016). Marco para la divulgación de información en las alianzas público-privadas. Grupo APP Banco Mundial. Washington, febrero 3.

Banco Mundial (2014). Public Private Partnership case studies: Traffic demand risk/The case of Bangkok's Skytrain (BTS). Washington, marzo. Recuperado de http://www.unescap.org/sites/default/files/ Case\%201\%20_Traffic\%20Demand_\%20Bangkok\%20BTS.pdf

Banco Mundial, (2014). Guía de referencia Asociaciones Público-Privadas versión 2.o. Washington.

Banco Mundial (2016). [WBG_PPP] (20 de junio). Sociogramas elaborados con los tuits recuperados de la cuenta de twitter. Recuperado de https://twitter.com/WBG_PPP

BARRETO, S. (2016). "Introducción a las asociaciones público-privadas en Colombia". Bogotá: Universidad Externado de Colombia, 1. ${ }^{\text {a }}$ ed., 211 p.

Bellod, J. F. (2015). "Asociación Público-Privada: el caso de la Desaladora de Escombreras", en Revista Auditoría Pública. Recuperado de http://www.auditoriapublica.com/h emeroteca/ Auditor\%C3\%ADa\%20P\%C3\%BAblica\%20n\%C2\%BA\%2066\%20pag\%2065-74.pdf

BousSAGUET, L. y otros. (2009). Diccionario de políticas públicas, Bogotá: Universidad Externado de Colombia, 1. ${ }^{\text {a }}$ ed.

BENAVIDES, J. y otros. (2012). Concesiones viales: construyendo transparencia. Fedesarrollo, Bogotá. BENAVIDES, J. (2010). Debates presidenciales. CAF FEDESARROLLO. Bogotá. 
BENAVIDES, J. L. (2014). Estudios sobre el régimen jurídico de las asociaciones público-privadas. En Temas de Derecho Administrativo. Bogotá: Universidad Externado de Colombia.

Bull, A. (2004). Concesiones viales en América Latina: situación actual y perspectivas. Comisión Económica para América Latina CEPAL. Serie recursos naturales e infraestructura. Naciones Unidas, Santiago de Chile.

BuLL, M. y otros (2017). Toll-Road PPPs. Identifying, Mitigating and Managing Traffic Risk. PPIAF, Global Infrastructure Facility. World Bank Group. Washington.

Breteau, P. y otro. (2015). "Partenariats public privé: un dispositif de plus en plus décrié", en Le Monde. Recuperado de http://www.lemonde.fr/les-decodeurs/article/2015/11/06/partenari ats-public-prive-un-dispositif-de-plus-en-plus-decrie_4804403_4355770.html.

BRUNETIÈRE, J. R. (2014). A quoi sert l'évaluation de l'action publique? En Évaluer les politiques publiques pour améliorer l'action publique. Trosa, Sylvie. Nouvelle Édition Recuperado de Vincennes: Institut de la gestion publique et du développement économique, Comité pour l'histoire économique et financière de la France. Disponible en internet: [http://books.openedition.org/igpde/1267]

CAICEDO, J. M. (2012). "Esquema contractual y asignación de riesgos" en Encuentro internacional de la Agencia Nacional de Infraestructura "La cuarta generación 4G de concesiones en Colombia" Bogotá 18 y 19 de septiembre, Recuperado de http://www.ani.gov.co/CMS/media/file/CCI\%20sobre\%20Esquema\%20 Contractual\%20Juan\%20Martin\%20Caicedo.pdf?bcsi_scan_4997aa96e5cd83cb=+Lv9BHuxg 2 dBErxeqt27OGJ5YHAHAAAAa0 mpag $==\&$ bcsi_scan_filename $=$ cci $\% 20$ sobre $\% 20$ Esquema $\% 20$ Contractual\%20Juan\%20Martin\%20Caicedo.pdf.

Cámara Colombiana de Infraestructura (noviembre 2014). Concesiones de Infraestructura de Cuarta Generación (4G): Requerimientos de inversión y Financiamiento Público Privado. Bogotá, noviembre 2014.

CAMPOS, M. J. (2012). "El control fiscal en la rendición de cuentas: el poder duro en el seguimiento y la evaluación de políticas públicas". Conferencia expuesta en XVII congreso internacional del CLAD sobre la reforma al Estado y de la Administración Pública. Recuperado de http://www.dgsc.go.cr/dgsc/ documentos/cladxvii/camposru.pdf.

Castaño, F. y Pérez, R. (2016). Avances normativos de la Contaduría General de la Nación en la Regulación de las Concesiones de Infraestructura de Transporte. Conferencia dentro del marco del Taller de Asociaciones Público Privadas entre el Banco Mundial y la Contaduría General de la Nación. Bogotá, marzo 8 al 10.

Ciénaga de la Virgen y el Viaducto (2016). ¿Desarrollo o destrucción? (Página web consultada el 28 de mayo). Recuperado de https://www.youtube.com/watch?v=MUYIIsmR7OK

Colombia Compra Eficiente (2013-2014), Sistema Electrónico de Contratación Pública SECOP. Sistema Electrónico de Contratación Pública, SECOP, Colombia compra eficiente: LICITACION PúBLICA VJ-VE-IP-LP-011-2013 (página web consultada del 26 de diciembre de 2013 al 15 de enero de 2014). Recuperado de https:/www.contratos.gov.co/consultas/detallePro ceso. do?numConstancia =13-19-1611882.

Congreso de la República (julio 12 de 2011). Estatuto Anticorrupción [Ley 1474 de 2011]. DO: 48128. Congreso de la República (enero 10 de 2012). Asociaciones Público-Privadas [Ley 1508 de 2012]. DO: 48308 .

Congreso de la República (noviembre 22 de 2013). Infraestructura de transporte [Ley 1682 de 2013]. DO: 48.982 . 
Congreso de la República (2013). Debate a la Ministra de Transporte en la Comisión VI del Senado de la República "Concesiones 4G". (Página consultada el 22 de mayo), Recuperado de https:// www.youtube.com/watch?feature=player_embedded \&v=4yQeixplAa4 .

Concesión Costera Cartagena Barranquilla (8 de junio 2016). (Página web consultada desde el 7 de mayo hasta el 30 de junio). Recuperado de http://www.concesioncostera.com/ Concesión Costera [Ccostera] (2016). Sociogramas elaborados con los tuits recuperados de la cuenta de twitter. Recuperado de https://twitter.com/CCostera.

Concesión Costera Cartagena Barranquilla (2016). Video Institucional. (Página web consultada el 28 de mayo). Recuperado de https://www.youtube.com/watch?v=jvjvZoNtopc

Concesión Costera Cartagena Barranquilla (2016). Video avance de obra viaducto ciénaga de la Virgen. (Página consultada el 28 de mayo). Recuperado de https://www.youtub e.com/ watch?v=9KkrDqd8Pp8.

Concesión Costera Cartagena Barranquilla (2016). Anillo Vial de Crespo fue inaugurado. (Página consultada el 28 de mayo). Recuperado de https://www.youtube.com/w atch?v=HMBdssUL7H8.

Consorcio Vía al Mar [cviaalmar] (8 de junio de 2016). Sociogramas elaborados a partir de tuits recuperados de esta cuenta. Recuperado de https://twitter.com/cviaalmar

Consejo de Estado (2013). Sala de Consulta y Servicio Civil. Exp. 2148 del 23 de agosto. Consejero Ponente: William Zambrano Cetina.

Consejo Privado de Competitividad (2012-2013), Informe Nacional de Competitividad.

Consejo Técnico de la Contaduría Pública (2014). Concepto 2014-298 CAPEX. Recuperado de http:// www.actualicese.com/normatividad/2015/Conceptos/C298-15.pdf

Contrato 503 de 1994. Concesión Vía al Mar. Concesión de primera generación. Recuperado de https://www.contratos.gov.co/consultas/detalleProceso.do?numConstancia=15-1-133681

Contraloría General de la República (2013). Función de advertencia "Concesiones viales y Asociaciones público privadas".

Contraloría General de la República (2009). Control Fiscal y participación privada en la prestación de servicios públicos y de transporte en el ámbito territorial.

Contraloría General de la República (2011). "La infraestructura en Colombia: vicisitudes del régimen contractual", en Revista Economía Colombiana, Bogotá, edición 332, septiembre.

Contraloría General de la República (2011). "Control Fiscal a Concesiones Viales". Recuperado de http:// www.camara.gov.co/portal2011/gestor-documental/doc_download/3590-concesi ones-viales $+\& \mathrm{hl}=\mathrm{es} \& \mathrm{gl}=\mathrm{co} \& \mathrm{pid}=\mathrm{bl} \& \mathrm{srcid}=\mathrm{ADGEESIYVDmrKtJB9GHBY} 5 \mathrm{~K} 6 \mathrm{DNta} 6 \mathrm{evGH} 3 \mathrm{~h} 6 \mathrm{GQDCelOuAYZ}-$ mwyK4ELEhAD5Ru7miiNyN_FyNTBq9Q_bf9M83KH-8-NAwTRw y_qy31IIU1 htm9Zfo35QTE7rj OXjHNDh7y7E0rhLznZm7\&sig=AHIEtbQ1e4abnzfen2B8XpWBvUK1d5cu-w.

Contraloría General de la República (2016). "Informe de auditoría a políticas públicas: infraestructura para la competitividad e integración regional Plan Nacional de Desarrollo 2010-2014 Prosperidad para todos". (Página consultada el 15 de mayo). Recuperado de http://www.contraloriagen.gov. co/documents/10136/186008126/024_APP_Infraestructura.pdf/f2b85a96-6c2e-4b43-9bf3689c2ececb67?version $=1.0$.

Contraloría General de la República (2011). "Informe consolidado de auditoría integral Instituto Nacional de Concesiones INCO boy ANI julio". 
Contraloría General de la República (2016). "Informe final de Auditoría Agencia Nacional de Infraestructura -ANI- Concesión Vial Cartagena-Barranquilla-Adicional 9 de junio de 2010 ".

Cour Des Comptes (2014). "Les partenariats public-privé du plan Hôpital 2007: une procédure mal maîtrisée". Rapport public annuel février. 49 p.

Cour Des Comptes (2015). "Les partenariats public-privé des collectivités territoriales: des risques à maitriser". Rapport public annuel 2015 -fevrier. Recuperado de https://www.google.com.co/?sa $=\mathrm{t} \& \mathrm{rct}=\mathrm{j} \& \mathrm{q}=\& \mathrm{es}$ $\mathrm{rc}=\mathrm{s} \&$ source $=$ web \&cd $=1 \& \mathrm{ved}=0$ ahUKEwivmMGej-HKAhUDFx $4 \mathrm{KHegCDCoQFggaMAA} \&=$ https $\%$ 3A\%2F\%2Fwww.ccomptes .fr\%2Fcontent\%2Fdownload\%2F79160\%2F1980604\%2Fversion\% 2F1\%2Ffile\%2F125-RP A2015-partenariats-public-prive.pdf\&usg=AFQjCNEL8xHb0t0nAqmzAL cWCrPAaw zJHA\&bvm=bv. $113370389, \mathrm{~d} . \mathrm{dmo \&}$ cad=rja $/$ https://www.ccomptes.fr/Actualites/Ala-une/Les-partenariats-public-prive-des-collectivites-territoriales-des-risques-a-maitriser.

CRÉPON et al. (2009-2010). "Méthodes d'évaluation des politiques publiques". Actes du séminaire. Ministère du budget, des comptes publics. París.

Cruz, C. (16 de diciembre de 2011). "Políticas públicas, una caja de berramientas". Cátedra Políticas públicas y control fiscal. Contraloría General de la República, Melgar. Grupo de Investigación Gobierno y Políticas Públicas Fundación José Ortega y Gasset Colombia.

DE LA Riva, I. (2017). "Nuevos modelos de financiación de infraestructuras públicas", en Revista Digital de Derecho Administrativo Universidad Externado de Colombia, edición n. ${ }^{\circ} 17,1{ }^{\text {er }}$ semestre, pp. 193-212.

Departamento Nacional de Planeación (2016). Nota Técnica 2-El concepto de Valorpor Dinero (VPD) y el comparador público privado (CPP). Recuperado de https://colaboracion.dnp.gov.co/CDT/Participacin\%20privada\%20en\%20proyectos\%20de\%20infraestructu/Nota\%20T\%C3\%A9cnica\%20 2\%202016.pdf.

Departamento Nacional de Planeación (2010-2014). Plan Nacional de Desarrollo "Prosperidad para todos", ts. I-II Recuperado de https://www.dnp.gov.co/PND/PND20102014.aspx.

Departamento Nacional de Planeación (1995). Conpes 2775 "Participación del sector privado en infraestructura física".

Departamento Nacional de Planeación (1999). Conpes 3045. "Programa de Concesiones Viales 1998 2000: Tercera Generación de Concesiones".

Departamento Nacional de Planeación (2001). Conpes 3107. "Política de Manejo de Riesgo Contractual del Estado para Procesos de Participación Privada en Infraestructura".

Departamento Nacional de Planeación (2001). Conpes 3133. "Modificaciones a la Política de manejo de riesgo contractual del Estado para procesos de participación privada en infraestructura establecida en el documento Conpes 3107 se abril se 2001".

Departamento Nacional de Planeación (2011). Conpes 3706 del 31 de octubre. "Importancia estratégica del programa "Corredores prioritarios para la prosperidad".

Departamento Nacional de Planeación (2009), Conpes 3615 de 28 de septiembre. "iniciativa para la modernización y gestión de activos fijos públicos".

Departamento Nacional de Planeación (2013). Conpes 3760 de 20 de agosto. "Proyectos viales bajo el esquema de Asociaciones Público-Privadas".

Departamento Nacional de Planeación (2013). Conpes 3761 de 20 de agosto. "Proyectos viales bajo el esquema de Asociaciones Público-Privadas: proyectos Pioneros". 
Departamento Nacional de Planeación (2016). "Asociaciones público privadas en infraestructura en Colombia" Dirección de Infraestructura y energía sostenible, Guías APP. Recuperado de https://www.dnp.gov.co/programas/participaci\%С3\%B3n-privada-\%20y-en-proyectos-deinfraestructura/asociaciones-publico-privadas/Paginas/guias-app.aspx

Departamento Nacional de Planeación (2012). "Guía de Buenas Prácticas para la ejecución de proyectos de Asociación Público-Privada", Ministerio de Hacienda y Banco Mundial.

Departamento Nacional de Planeación (2010). Evaluación al modelo de concesiones viales. Junio a diciembre.

Departamento Nacional de Planeación (2013). Asociaciones Público Privadas en Infraestructura en Colombia, en Seminarios Técnicos DNP, Dirección de Estudios Económicos. Bogotá, 20 de junio.

Departamento Nacional de Planeación (2016). Sistema de Seguimiento a Proyectos de Inversión. Avance de la concesión Cartagena-Barranquilla Contrato n. ${ }^{\circ} 503$ de 1994. (Página consultada el 30 de mayo). Recuperado de https://spi.dnp.gov.co/App_Themes/Segu imientoProyectos/ ResumenEjecutivo/0033000389999.pdf

Departamento Nacional de Planeación (2016). Sistema Sinergia. Balance al Plan Nacional de Desarrollo 2014-2018 a 2015. (Página consultada el 30 de mayo). Recuperado de https://sinergia.dnp.gov. co/Documentos\%20de\%20Interes/Balance_de_Resultados_PND_2015.pdf.

Departamento Nacional de Planeación (15 de agosto de 2014). Modificación al Decreto 1467 de 2012 [Decreto 1553 de 2014]. Recuperado de http://camacol.co/sites/default/files/base_datos_juridico/DECRETO\%20DNP\%20NACIONAL\%201553\%20DE\%202014.pdf

Departamento Nacional de Planeación (26 de mayo de 2015). Reglamentación del Sector Administrativo de Planeación Nacional. [Decreto 1082 de 2015]. Recuperado de https://www.dnp.gov.co/Paginas/ Normativa/Decreto-1082-de-2015.aspx

Diario La República (2016). Foro Infraestructura-El año de las vías $4 G$ retos y oportunidades de las vías del mañana (Página consultada el 24 de agosto). Disponible en Youtube. Recuperado de https:// youtu.be/nTvqDAca $8 z \mathrm{k}$

Economist Intelligence Unit (2014). Evaluating the environment for public-private partnerships in Latin America and the Caribbean: The 2014 Infrascope. EIU, New York, NY. Recuperado de http://idbdocs. iadb.org/wsdocs/getDocument.aspx?DOCNUM=39560904

FERNÁNDEZ, P. (2008). Valoración de opciones reales: Dificultades, problemas y errores, en CIIF, IESE, Business School. Universidad de Navarra. Documento de Investigación DI-760. Barcelona, España. FitzMaurice, R. (2016). Costera 4G toll road, Colombia, en IJGLOBAL (Página consultada el 13 de Agosto). Recuperado de https://ijglobal.com/Articles/101433

FLYVBJERG, B. y otros. (2016). "How (in) accurate are demand forecasts in public works projects?" (Página consultada el 9 de mayo). Recuperado de http://www.honolulutraffic .com/JAPAFlyvbjerg05.pdf

FORCAEL, E. et al. (2013). Aplicación del método de opciones reales en la valoración de proyectos inmobiliarios. Obras y proyectos 14, 58-70.

European PPP Expertise Centre (EPEC) (2008). "A guide to guidance sourcebook for PPPs in Ten-Transport". European Commission. Luxembourg. Recuperado de http://ec.europa.eu/regional_policy/ sources/docgener/guides/ppp_en.pdf

GÓMEZ, F. y otros (2006). Evaluación económica de la experiencia colombiana en concesiones de servicios públicos e infraestructura. Tesis de Grado. Universidad de los Andes, Bogotá, 157 pp.

GÓmEZ, I. D. (2012.). El derecho de la contratación pública en Colombia. Bogotá, 2. ${ }^{a}$ ed. Editorial Legis. 
GÓmeZ, L. (2015). Taller de Análisis de las Políticas Públicas. Conferencia realizada en Taller de trabajo de Políticas Públicas, Bogotá, Contraloría General de la República. 14 al 16 de octubre.

González, J.; Rojas, M.; Arboleda, C. y Botero, S., "Project Finance y Asociaciones PúblicoPrivadaa para la provisión de servicios de infraestructura en Colombia", en Obras y Proyectos 16, 2014.

GuASCH, J. L. (2016). Granting and renegociating infrastructure concessions. World Bank Publications. (Página consultada el 9 de mayo). Recuperado de https://openknowledge.worldbank.org/ bitstream/handle/10986/15024/288160PAPER0Granting010renegotiating.pdf? sequence $=1$.

GUILBERT, T. (2013). Stades, prisions, hôpitaux: dangers et dérives des partenariats public-privé. En l'Obs. (Página consultada el 29 de abril). Recuperado de http://leplus.nouvelobs.com/contribution/802797stades-prisons-hopitaux-dangers-et-derives-des-partenariats-public-prive.html.

HERnÁNDEZ, A. (2008). "La responsabilidad contractual del Estado: ¿una responsabilidad sin imputación?", en Revista de Derecho Privado n. 14. Bogotá: Universidad Externado de Colombia.

HinOjOSA, S. (2012). Opciones reales y Evaluación de proyectos de infraestructura pública: Un eslabón que falta. Puebla, México. (Página consultada el 14 de Septiembre de 2016). Recuperado de http://www. cepal.org/ilpes/noticias/paginas/7/53027/SERGIO_HINOJOSA_Opc_Reales_EPIP.pdf.

Kerali, H. (2013.). Visión General de HDM-4. World Road Association. Versión 1. Colección de la serie de Desarrollo y Gestión de Carreteras. Banco Mundial.

KyozuKA, T. (2016). Bangkok's skytrain operator has its eye on the future, en Nikkei Asian Review. Recuperado de http://asia.nikkei.com/Business/Companies/Bangkok-s-SkyTrain-operatorhas-its-eye-on-the-future?page $=2$.

LASPRILla, C. (2014). Concesiones de Infraestructura en materia de transporte. Primer Encuentro Networking Arquitectura-Ciudad. Bogotá, Universidad Javeriana, Marzo 11.

LE GALES, P. (1995). Aspects idéologiques et politiques du partenariat public-privé, en Revue D'économie Financière. Recuperado de http://www.jstor.org/stable/42905491.

LEWIS, C. (2016). "Líos jurídicos en compra de predios, "el dolor de cabeza" de los concesionarios viales", en Revista Portafolio. (Página consultada el 1 de agosto). Recuperado de : http:// www.portafolio.co/economia/proyectos-viales-en-riesgo-por-lios-juridicos-en-la-comprade-predios-498938.

MANCIPE, J. (2014). Las APp y los nuevos retos en la gestión de asuntos públicos, en Revista Ámbito Jurídico. Recuperado de http:// http://www.ambitojuridico.com/BancoConocimiento/ N/ noti141909-11las_app_y_los_nuevos_retos_en_la_gestion_de_los_asuntos_publicos/noti 141909-11las_app_y_los_nuevos_retos_en_la_gestion_de_los_asuntos_publicos.asp?Mig a =1 .

MEDELLín, P. La política de las políticas públicas: propuesta teórica y Metodológica. Santiago de Chile, CEPAL., julio 2004.

Ministerio de Transporte (2013). La cuarta generación de concesiones viales. (Página consultada entre el 3 de mayo y el 20 de junio). Recuperado de https://www.mintransporte.gov.co

Mereg, H. (2014). Aspectos Financieros de las Asociaciones Público Privadas, en Conferencia Asociaciones Público Privadas. Bogotá, Universidad Externado de Colombia. Agosto 21.

Ministerio de Hacienda (2013.). Manejo de Pasivos Contingentes. Dirección de Crédito Público y Tesoro Nacional. Presentación de Power Point.

Ministerio de Hacienda (2011.). Metodología valoración y seguimiento de riesgos en contratos estatales. 
Ministerio de Transporte (2013). Corredor Cartagena Barranquilla: una vía ágil y moderna para la Costa Caribe colombiana. (Página consultada el 26 de mayo). Recuperado de https://www.mintransporte. gov.co/publicaciones. php?id=2883

Ministerio de Transporte (2016). Visita de obra viaducto Ciénaga de la Virgen. (Página Consultada el 28 de mayo). Recuperado de https:/www.youtube.com/watch?v=jvjvZoNtopc

MONTEIRO, R. (2016). Riesgos contingentes asociados a las APP. Conferencia presentada en el Taller de Asociaciones Público Privadas /Concesiones. Banco Mundial y Contaduría General de la Nación. Bogotá, marzo 8 al 10.

National Audit Office (2011). "Lessons from PFI and other Projects-Report by the comptroller and Auditor General" HC 920 Session 2010-2012. London, 29 April. 36 pp.

National Audit Office (2010). "The performance and management of hospital PFI contracts-Report by the comptroller and Auditor General" HC 68 Session 2010-2011. London, 9 pp.

Ordoñez, G. (2013). Manual de análisis y diseño de Políticas Públicas. Bogotá: 1. a ed., Universidad Externado de Colombia.

Osuna, F. (enero-marzo de 2013). Alianzas público-privadas: la clave está en las instituciones. Oportunidades y retos en Colombia, en Perspectiva, Bogotá, Edición 31.

PAREJA, J. (2008). Estimación de la volatilidad en opciones reales para un proyecto en Colombia. Semillero de Investigación Bufete Financiero, Universidad Eafit. Recuperado de http://www.eafit.edu.co/ investigacion/comunidad-investigativa/semilleros/bufete-financiero/Documents/Paper\%20 Inv.pdf

Perilla, C. J. (2007). La política pública seguridad democrática 2002-2006. Tesis de Maestría. TM 320.9861 P444P 125 H. Biblioteca Universidad Externado de Colombia.

PENING, J. P. (2014). Aseguramiento y riesgos sociales, ambientales y prediales de la $4 \mathrm{G}$ de concesiones, Departamento Nacional de Planeación Recuperado de http://www.ani.gov .co/CMS/media/file/Aseguramiento \%20y\%20Riesgos\%20Sociales, \%20Ambientales\%20y\%20Prediales\%20Jean\%20 Philippe\%20Pening.pdf

Pening, J. P. (2014). Asociaciones Público Privadas, en Conferencia Asociaciones Público Privadas. Bogotá: Universidad Externado de Colombia. Agosto 21.

PÉrez Sotelo, R. (2016). Avances Normativos de la CGN en la Resolución de las Concesiones de Infraestructura de Transporte, en Taller de Asociaciones Público Privadas Banco Mundial, Bogotá, marzo 8 al 16.

Presidencia de la República (2016). "Concesión vial Cartagena-Barranquilla coloca bonos por USD \$263 millones" (página consultada el 1 de agosto). Recuperado de http://es.presidencia.gov.co/ noticia/160706-Concesion-vial-Cartagena-Barranquilla-coloca-bonos-por-USD-263-millonesy-recibe-voto-de-confianza-de-los-mercados

Presidencia de la República (julio 6 de 2012). Reglamentación de la Ley 1508 de 2012 [Decreto 1467 de 2012]. DO: 48483.

Presidencia de la República (julio 17 de 2013). Sistema de Compras y Contratación Pública [Decreto 1510 de 2013]. DO: 48854.

Programa "Pièces à conviction" (2012). Partenariat public privé. Recuperado de https://www.youtube. com/watch?v=Gjuw - BUmMjc. 
Programa para el impulso de Asociaciones Público-Privadas en Estados Mexicanos (2009). "Asociaciones Público-Privadas para el Desarrollo de infraestructura y la provisión de Servicios Públicos", informe final- Experiencia del Reino Unido. Ciudad de México, Fondo Multilateral de Inversiones Banco Interamericano de Desarrollo.

Resolución 1382 del 29 de octubre de 2015. Por la cual se otorga una licencia ambiental y se toman otras determinaciones. Emitida por la Autoridad Nacional de Licencias Ambientales. ANLA. Recuperado de http://www.anla.gov.co/sites/default/files/res_1382_29102015.pdf

RestrePO, M. (2014). "Ingeniería colombiana en aprietos", en El Colombiano (página consultada el 27 de abril). Recuperado de http://www.elcolombiano.com/BancoConocimi ento///ingenieria_colombiana_en_aprietos/ingenieria_colombiana_en_aprietos.asp

Roth, A. N. (2008). "Perspectivas teóricas para el análisis de las políticas públicas: ¿De la razón científica al arte retórico?", en Estudios políticos, Medellín: Universidad Nacional, julio-diciembre.

RodAs, P. (2012). Misión del Sistema de Ciudades conectividad interurbana. Bogotá Diciembre de 2012. Departamento Nacional de Planeación.

RodríGueZ, C. (2016). "Hay que acelerar los desembolsos para las vías 4G". Diario La República (página consultada el 25 de agosto). Recuperado de http://www.larepublica.co/\%E2\%80 \%9Chay-que-acelerar-los-desembolsos-para-las-v\%C3\%ADas-4g\%E2\%80\%9D413951

RODRÍGUEZ, L. (2015). "Auditoria gubernamental de política pública: el caso de la auditoría al Plan Agro 2003-2015 para la agricultura y la vida rural en las Américas", en Revista Auditoría Pública. Recuperado de http://www.auditoriapublica.com/hemeroteca/Pag\%2051-58\%20\%20 n\%C2\%BA\%2063.pdf

ROZAS BALBONTIN, P. y otros. (2012). El financiamiento de la infraestructura propuestas para el desarrollo sostenible de una política sectorial. Naciones Unidas, Comisión Económica para América Latina CEPAL.

Rufián, D. (2002). Políticas de Concesión Vial: análisis de las experiencias de Chile, Colombia y Perú. Instituto Latinoamericano y del Caribe de Planificación Económica y Social (ILPES), Santiago de Chile: CEPAL.

SARMIENTO, R. (2014). Reglamentación de riesgos en concesiones y APP, en Conferencia Asociaciones Público Privadas. Bogotá: Universidad Externado de Colombia. Agosto 21.

SAUSSIER, S. (2015). Les partenariats public-privé: une oportunité? En IAE de Paris. Recuperado de https:// www.youtube.com/watch?v=x1T8JIAW2Xo

STANDARD y POOR'S (2016). "The Anatomy of Construction Risk: Lessons from a Millennium of PPP Experience". Harvard Business School. (Página consultada el 25 de agosto). Recuperado de http://www. robbain.com/The\%20Anatomy\%200f\%20Construction\%20R isk.pdf.

Senado de Francia (2014). Informe ante la comisión de Leyes Constitucionales sobre las Asociaciones Público Privadas. Registrado en la Presidencia del Senado el 16 de julio. Aprobado en Sesiones Extraordinarias de 2013-2014.

Sistema Electrónico de Contratación Pública - SECOP (2013). Recuperado de https://www.contratos. gov.co/consultas/detalleProceso.do?numConstancia =13-19-1611882

Sociedad Colombiana de Ingenieros (2014). Concepto técnico para la Reglamentación de la Ley 1681 de 2013. Bogotá, febrero.

Surel, Y. (2014). Conferencia Políticas Públicas, en Foro Políticas Públicas. Contraloría General de la República. Recuperado de https://m.youtube.com/watch?feature=youtu .be\&v=GKaPhr-aDig 
VAn SCHAIK, F. (2016). Contabilidad para Alianzas Público-Privadas (APP) y Contratos de Concesión. Conferencia presentada en el Taller de Alianzas Público Privadas Banco Mundial y Contaduría General de la Nación. Bogotá, marzo 8 al 10.

Vargas Riaño, O. G. Ponz Tienda, J. L. y Jaramillo Berrocal, C. A. (2014). Análisis comparado de la valoración de costos y riesgos compartidos en proyectos de cuarta generación de concesiones viales en Colombia (Tesis (Magíster en Ingeniería Civil). Universidad de los Andes). Bogotá: Uniandes. http://biblioteca.uniandes.edu.co/acepto1201420.php?id=4777.pdf.

VASALLO, J. (2010). Infraestructura pública y participación privada: conceptos y experiencias en América y España. Corporación Andina de Fomento.

Velásquez Montaño, J. P.; Zea Gómez, C. y Zambrano Riveros, J. A. (2015). Valoración por opciones reales: aproximación a la nueva generación de autopistas $4 G$ (Tesis (Economista). Universidad de los Andes). Bogotá: Uniandes. http://biblioteca.uniandes.edu.co/acepto2015101.php?id=5788.pdf VILLAREAL, J. (2016). Ingeniería financiera en proyectos APP. Análisis de Riesgos. Universidad de los Andes. $76 \mathrm{p}$.

XION, WeI et al. (2014). Concession Renegotiation models for projects developed through PublicPrivate Partnership, en Journal of Construction and Engineering Management, 2014. n. ${ }^{\circ}$ 140. Edición 5. 9 p.

YEPES, T. y otros. (2012). "Infraestructura de Transporte en Colombia: ¿Luz al final del túnel?, en Tendencia Económica n. ${ }^{\circ}$ 125. FEDESARROLLO, informe mensual, Bogotá, noviembre.

ZAMBRANO, O. (2011). Brechas de Infraestructura, crecimiento y desigualdad en los países andinos. Banco Interamericano de Desarrollo, mayo.

ZANINOVICH, D. (2014). Dotaciones concesionadas para un buen gobierno, en Primer Encuentro Networking Arquitectura Ciudad. Bogotá: Pontificia Universidad Javeriana, marzo 11. Recuperado de https://www.dropbox.com/home/1er\%20Encuentro\%20Networking\%20Arquitectura-Ciudad

ZuRITA, F. (2001). "La tasa de descuento revisitada", en Documento de trabajo n. ${ }^{\circ} 261$. Santiago, Pontificia Universidad Católica de Chile. ISSN: 0717-7593. 